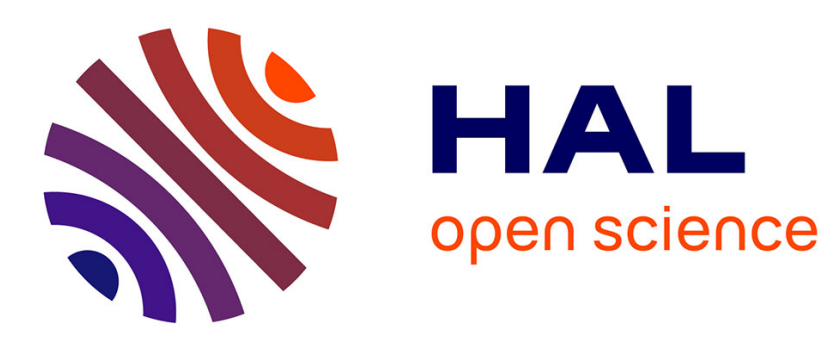

\title{
A review about the effects of structural and operational factors on the gigacycle fatigue of steels
}

\author{
Dalenda Jeddi, Thierry Palin-Luc
}

\section{To cite this version:}

Dalenda Jeddi, Thierry Palin-Luc. A review about the effects of structural and operational factors on the gigacycle fatigue of steels. Fatigue and Fracture of Engineering Materials and Structures, 2018, 41, pp.969-990. 10.1111/ffe.12779 . hal-01812536

\section{HAL Id: hal-01812536 https://hal.science/hal-01812536}

Submitted on 11 Jun 2018

HAL is a multi-disciplinary open access archive for the deposit and dissemination of scientific research documents, whether they are published or not. The documents may come from teaching and research institutions in France or abroad, or from public or private research centers.
L'archive ouverte pluridisciplinaire HAL, est destinée au dépôt et à la diffusion de documents scientifiques de niveau recherche, publiés ou non, émanant des établissements d'enseignement et de recherche français ou étrangers, des laboratoires publics ou privés. 


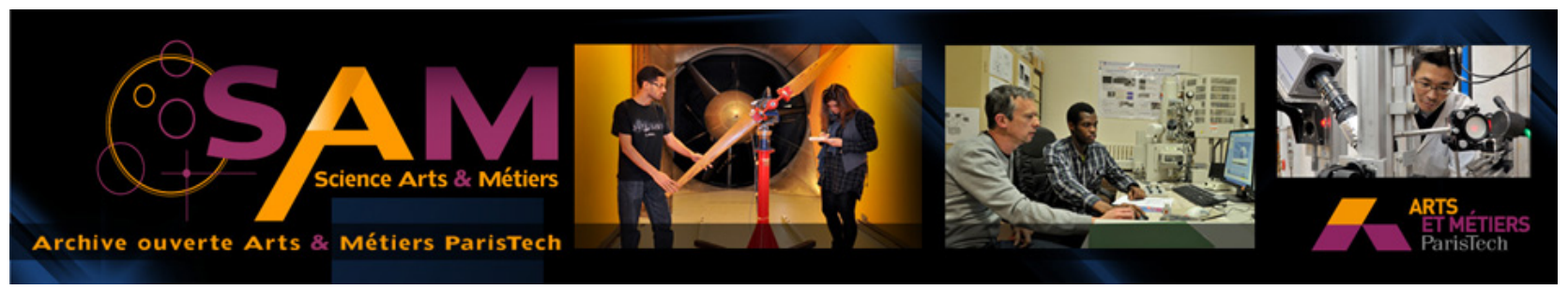

Science Arts \& Métiers (SAM)

is an open access repository that collects the work of Arts et Métiers ParisTech researchers and makes it freely available over the web where possible.

This is an author-deposited version published in: http://sam.ensam.eu Handle ID: .http://hdl.handle.net/null

\section{To cite this version :}

Dalenda JEDDI, Thierry PALIN-LUC - A review about the effects of structural and operational factors on the gigacycle fatigue of steels - Fatigue and fracture of engineering materials and structures - Vol. 41, p.969-990 - 2018 


\title{
A review about the effects of structural and operational factors on the gigacycle fatigue of steels
}

\author{
D. Jeddil T. Palin-Luc ${ }^{2}$
}

\author{
${ }^{1}$ University of Tunis El Manar, Laboratory \\ of Applied mechanics and Engineering, \\ Campus Universitaire El Manar, BP 37, \\ 1002 Tunis, Tunisia \\ ${ }^{2}$ Arts et Metiers ParisTech, CNRS, I2M \\ Bordeaux, Esplanade des Arts et Metiers, \\ 33405 Talence Cedex, France

\section{Correspondence} \\ T. Palin-Luc, Arts et Metiers ParisTech, \\ CNRS, I2M Bordeaux, Esplanade des Arts \\ et Metiers, 33405 Talence Cedex, France. \\ Email: thierry.palin-luc@ensam.eu
}

\begin{abstract}
It is well-known that the high cycle fatigue (HCF) strength of steel components is influenced by a lot of factors depending on both material, loading (including environment), specimen or component geometry (design), and manufacturing process. Based on a literature review of a lot of experimental data, a synthesis is proposed in this paper to discuss the effect of the structural and operational factors on the very high cycle fatigue (VHCF) characteristics of steels. HCF and VHCF regimes are distinguished in terms of failure mechanisms and $S-N$ curve shapes for high and low strength steels. Then, the effect of the microstructural and mechanical features on the VHCF resistance is debated as different parameters (microstructure, inclusion size type and depth, hydrogen, environment, maximum tensile strength, and residual stresses). Next, the influence of the loading conditions is addressed by taking into account both the frequency effect, the highly stressed volume, the loading type, and loading ratio. Finally, the influence of the testing techniques used in VHCF experiments is discussed.
\end{abstract}

\section{KEYWORDS}

crack initiation, gigacycle fatigue, influence factors, micromechanism, steel

\section{1 | INTRODUCTION}

In many industrial sectors such as automotive and aeronautics, the design of mechanical components against fatigue crack initiation is based on fatigue strength data in the high cycle fatigue (HCF) regime (ie, around $10^{7}$ cycles). However, in the last 30 years, experimental researches have shown that, despite stresses below the conventional fatigue "limit" (ie, strength in HCF regime), there are fatigue failures beyond $10^{9}$ cycles or more. Bathias et $\mathrm{al}^{1,2}$ found out that the fatigue strength decreases approximately 50 to $200 \mathrm{MPa}$ from $10^{6}$ to $10^{9}$ cycles depending on the material. To study the gigacycle fatigue strength beyond $10^{8}$ cycles with reasonable testing times, new testing techniques based on ultrasonic loading frequencies of 20 or $30 \mathrm{kHz}$ have been developed for the last 25 years. ${ }^{3,4}$ Nevertheless, the influence of the frequency on the fatigue strength of materials is a complex subject and remains controversial in the literature. ${ }^{5-7}$ Indeed, a high frequency can lead to self-heating of the specimen that may induce instability of the microstructure and degradation or improvement of the mechanical properties of the material, which in turn, depend both on the loading type and on the operating environment.

The approach in this review paper has been chosen to classify steels in low or high strength steels and stainless steels, taking into account their different behaviors under ultrasonic frequency. Furthermore, the experimental results shown in this paper have been intentionally selected from researches carried out since the nineties. Indeed, the progress of computer and electronics control has led to more reliable results. 
It is well known that both metallurgical characteristics and loading conditions deeply influence the HCF strength of metals and metallic alloys and components. ${ }^{8}$ Metallurgical parameters are inherent to thermo-mechanical operations (or history) needed to produce any component with its final properties, namely surface roughness, hardness, tensile strength, monotonic and cyclic behavior, microstructure, and residual stresses. The loading conditions include the type of loading (tension, compression, plane or rotative bending, torsion and their combination, biaxial tension), loading ratio, loading frequency, and environment (temperature, humidity, gaseous environment, corrosive agent, etc.). Additionally, as it will be shown in this paper, the testing device could influence the gigacycle fatigue strength of steels because of both the loading frequency and the specimen size. These are, respectively, called the frequency effect and the size effect. It will be shown hereafter that the VHCF strength of steels includes all these parameters.

In this context, the investigation presented in this paper is based on the discussion of the effect of the structural and operational factors on the VHCF characteristics of steels. Firstly, high cycle fatigue (HCF) and VHCF regimes are distinguished in terms of failure mechanisms and $S$ - $N$ curve shapes. Then, the effect of the microstructural and mechanical features on the VHCF resistance is debated as different separable parameters. Next, the influence of the loading conditions is addressed by taking into account both the frequency effect, the loading type, and loading ratio. Finally, the testing techniques used in VHCF are discussed.

\section{2 | FROM HIGH CYCLE FATIGUE (HCF) TO VERY HIGH CYCLE FATIGUE (VHCF) OF STEELS}

\section{1 | Mechanisms of fatigue failure in the gigacycle fatigue regime}

It is now well established that the fatigue failure is the result of 2 mechanisms: the initiation and then propagation of cracks. Generally, engineers opt for surface treatment(s) to improve the fatigue strength of materials because crack initiation usually* occurs at the surface of components in the HCF regime. Consequently, surface layers are harder than the core to delay crack initiation, and the ductile core resists to the propagation of cracks. However, in the VHCF regime, most of the crack initiations occur in the core of the components or specimens.

*The case of high internal tensile residual stresses is not considered here because industrial engineers usually avoid such a critical case on components.
It seems that cyclic plastic deformations at the surface (in the plane stress condition) become so small that cracks initiate elsewhere. In this case, internal defects (inclusions) or large grains play a key role, whereas the surface plays a minor role especially if it is smooth ${ }^{1}$ and without any aggressive environment. For instance, for JIS SUJ2 high strength steel, fatigue fracture of untreated and 2 shot-peened specimens occurred in VHCF regime by the internal fracture mode, and no difference in fatigue life between them could be seen under tensioncompression loading. ${ }^{9}$

For high strength steels, inclusions play a very important role in gigacycle fatigue; they act as a "notch."10,11 Murakami et $\mathrm{al}^{12}$ pointed out the presence of a particular morphology called optically dark area (ODA) beside the inclusion at the center of the fish-eye mark as shown in Figure 1. When an ODA is observed by SEM with the electron beam being normal to fracture surface, ODA surface is observed as granular. This typical granular morphology is also named fine granular area (FGA) $)^{13-15}$ or granular bright facet (GBF) ${ }^{9,16,17}$ For simplicity, because ODA, FGA, and GBF named the same typical area on the fracture surface of a specimen tested in the VHCF regime, such area is named FGA hereafter. It was reported that in the VHCF regime, more than $90 \%$ of the fatigue life is attributed to the creation of the FGA. ${ }^{11,15,18}$ It has been demonstrated that the FGA formation during the very long fatigue process controls the internal fracture mode. FGA is assumed to play a crucial role in the failure mechanism in the VHCF regime. ${ }^{16,19}$ According to Grad and Kerscher, ${ }^{20}$ the critical role of internal inclusions in VHCF compared with the role of surface ones is related to a change in the crack

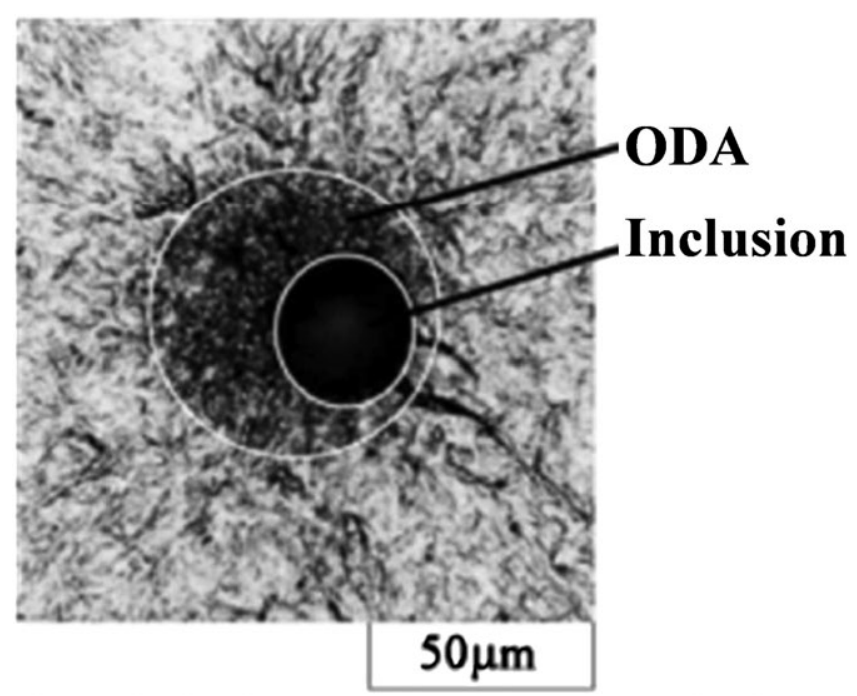

FIGURE 1 Optical micrograph of ODA (named FGA in the following) $)^{12}$ 
propagation rates at the surface compared with the core, especially when the loading is small, close to the threshold of the stress intensity factor range.

Several explanations have been proposed for explaining the formation of this specific feature of the fracture surface in the VHCF regime. ${ }^{19,21}$ These are hydrogen embrittlement-assisted cracking caused by hydrogen that is trapped by the inclusions, ${ }^{22}$ fracture of boundaries between spherical carbide particles and matrix, ${ }^{23}$ or the formation of a fine granular layer by polygonisation and debonding between inclusion and matrix. ${ }^{24,25}$ Recently, Pineau and Forest ${ }^{26}$ have shown that cyclic plastic strain localization around inclusions is very dependent on both the elastic misfit properties of inclusions and metal matrix and the residual stresses around inclusions due to the difference of the thermal expansion coefficients of matrix and inclusion. Such materials with defects are named "Type II" by Mughrabi (ie, non pure metals and industrial alloys), whereas pure materials and alloys are name "Type I."

At the microscopic level, and on defect free materials (Type I), Mughrabi showed that the initiation of a fatigue crack in the gigacycle fatigue regime can be described in terms of the microstructurally irreversible portion of the cumulative cyclic plastic strain. ${ }^{27}$ Indeed, after very many cycles $\left(>10^{9}\right)$, a surface roughness can develop very slowly, due to very small remnant cyclic slip irreversibilities of dislocation to-and-fro glide at the surface. ${ }^{28,29}$ So, during the cyclic deformation, dislocation interactions lead to the formation of irreversible plastic deformation.
This cyclic irreversible plastic deformation accumulates during the fatigue loading and leads to localization of plastic deformation and finally to crack initiation at the sites of stress concentration. ${ }^{28}$

Very recently, Stanzl-Tschegg ${ }^{30}$ showed that on “Type I" material (high-purity copper), internal fatigue crack initiation can be observed in the VHCF regime, but $10^{10}$ cycles were needed to observe that. The reason of such initiation is still unknown even if short cracks (20 $\mu \mathrm{m}$ long) seem to play the role of newly existing defects. For this copper, this characteristic length of $20 \mu \mathrm{m}$ seems to be the threshold for arrested or growing cracks. Because of the anisotropic elastic behavior of the grains and the discrete nature of the slip systems, the shape of the grains and their crystallographic orientation with regard to the cyclic loading play a key role on the microscopic plastic strain localization and short crack propagation.

A few years ago, "non-inclusion induced crack initiation" has been observed in bainite/martensite ${ }^{25,31}$ or ferrite/ martensite ${ }^{32}$ multiphase steels. The crack did not initiate from inclusion but within the matrix (Figure 2). For instance, $\mathrm{Chai}^{32}$ reported this phenomenon (termed as subsurface non-defect fatigue crack origins-SNDFCO) in ferrite/martensite 2 phase steel. The initiation of SNDFCO is a material damage process caused by cyclic plastic deformation in the soft phase (such as ferrite and austenite) due to deformation mismatch between 2 phases. On "Type II" and on multiphase materials, the complexity of the microstructure in terms of elastic
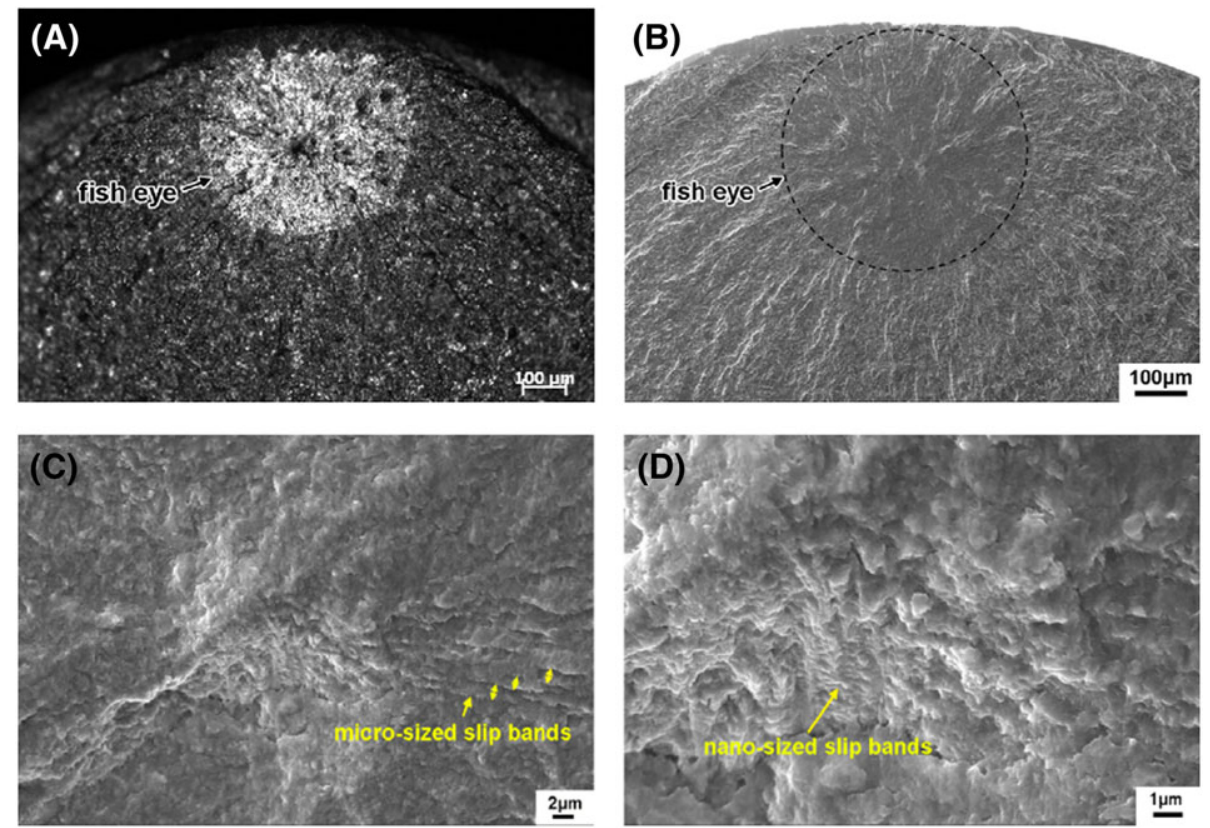

FIGURE 2 Non-inclusion induced fracture surface in VHCF of bainite/martensite multiphase steel, $(\mathrm{Rm}=1320 \mathrm{MPa})$, in tensioncompression $(R=-1)$ under a loading frequency of $20 \mathrm{kHz}$, (A) optical image, (B) SEM image, (C) FGA, and (D) detailed observation of FGA $^{31}$ [Colour figure can be viewed at wileyonlinelibrary.com] 
anisotropy of the grains, different yield strength and cyclic behavior of each phases, and grain morphologies will lead to a strong interaction with the crack initiation mechanism and then the propagation of microstructurally short cracks. This has been illustrated for instance by Tofique et $\mathrm{al}^{33}$ on a hot rolled stainless steel. Krupp et $\mathrm{al}^{34}$ have also shown on a martensitic steel that the crack initiation and early crack growth are strongly influenced by the orientation of the martensite blocks.

For low strength steels, in VHCF regime, cracks would not initiate at inclusions but at the surface..$^{6,10,35,36}$

Further researches show that crack initiation in VHCF regime depends on the loading type. ${ }^{15}$ For instance, under cyclic axial loading, the VDSiCr spring steel displays crack initiation at internal inclusion. However, under torsion loading, the initial crack is produced by cyclic shear, in the interior or at the surface. ${ }^{15}$ More details of the fatigue failure mechanisms in VHCF regime are summarized in Table 1 based on some examples collected from literature.

\section{2 | $S$ - $N$ curve characteristics of steels}

Since, the $19^{\text {th }}$ century, the fatigue limit has been defined as the asymptotic tendency of the $S$ - $N$ curve (Figure 3) observed in HCF regime between $10^{6}$ and $10^{7}$ cycles for steels. ${ }^{\dagger}$ It was presumed that beyond this fatigue "limit," there was no failure. It was established that the major part of fatigue life is spent during crack propagation, whereas the fraction of fatigue life spent during initiation is usually much smaller. In the 30 recent years, the industrial technology development has led to some machine components failures beyond $10^{7}$ cycles, and consequently, the asymptote might not exist in some cases of $S$ - $N$ curves of steels. ${ }^{1,24,47}$ Bathias et al suggested to ban the fatigue limit concept, and to replace it by fatigue strength for a considered number of cycles. ${ }^{1}$

In this section, the $S-N$ curves of steels are described in connection with their "shape." Thus, we distinguish between very high strength steels (the tensile strength is higher than $1100 \mathrm{MPa}$ ) and low strength steels. Indeed, the $S$ - $N$ curves of some low-strength steels can show a horizontal asymptote that could be named "fatigue limit" $36,40,41$ up to the tested life ( $10^{9}$ or $10^{10}$ cycles) at least. Notwithstanding this, nobody can guarantee that testing a specimen or component up to $10^{11}$ cycles will not break it. However, the $S$ - $N$ curves of high-strength steels do not have any clear horizontal asymptote. They will eventually fail with increasing the number of cycles. ${ }^{17,48}$

\footnotetext{
${ }^{\dagger}$ This is not the case for all the materials and alloys. For instance, it is known for more than 50 years that there is no asymptotic tendency of the SN curves in aluminium alloys, but this is out of the scope of this paper.
}

\subsection{1 | S-N curve characteristics of high strength steels}

Many studies carried out on very high strength steels show a step-wise $S-N$ curve consisting of 2 parts, short life regime up to around $10^{5}$ cycles, and long life regime for more than $10^{7}$ cycles (Figure 4). Such $S-N$ characteristic is attributed to different mechanisms on smooth specimens: initiation at the surface or internal one leading to a fish-eye typical cracking in relation with inclusions. ${ }^{48,49}$ The horizontal part of the $S-N$ curve, ie, the transition stress amplitude for which the crack initiation changes from surface to subsurface is the conventional fatigue limit when fatigue tests are censored at $10^{7}$ cycles. $^{49,50}$ Nevertheless, for notched specimens or when roughness is high, a few specimens failed between $10^{7}$ and $10^{10}$ cycles. This is because the surface roughness (especially the valleys of the roughness profile) act as small notches ${ }^{2,50}$ (Figure 5). One note, with a further increase of the surface roughness, ie, much higher stress concentration, that cracks always initiate at scratch marks on the specimen surface. This means that fatigue strength would be decreased significantly and step-wise $S-N$ curve would not appear anymore. $^{50}$

Other studies show $S$ - $N$ curve with a duplex shape (Figure 6) corresponding to different fracture modes in super-long life range, beyond $10^{6}$ cycles. In this case, fish-eye crack initiation was not observed in all the specimens, and crack initiation also occurred at the surface. ${ }^{13,17,47,51}$

It is also important to note that for the $42 \mathrm{CrMo}$ high strength steels with different molybdenum contents prepared by special technology leading to zero inclusion in the material, ${ }^{10}$ the range of failure cycles is less than $2 \times 10^{6}$ cycles and a horizontal asymptote lies between $2 \times 10^{6}$ and $10^{9}$ cycles.

Overall, for high strength steels under tension-compression loading at $20 \mathrm{kHz}$, the fatigue strength at $10^{9}$ cycles, in terms of stress amplitude, varies from 600 to $1000 \mathrm{MPa}$. It depends on the specific treatment undergone to the material ${ }^{2,15,17,36,37,39,40,49,5142,52-54}$ (Table 2). Furthermore, different studies show that for the high strength steels, the difference between the fatigue strength at $10^{6}$ and $10^{9}$ cycles is ranging from 50 to $200 \mathrm{MPa}^{1,2}$

\subsection{2 | S-N curve characteristics of low strength steels}

It was pointed out by different studies that in the case of low strength steels (maximum tensile strength $\leq 1100 \mathrm{MPa}$ ), fatigue crack initiation mainly occurs at 


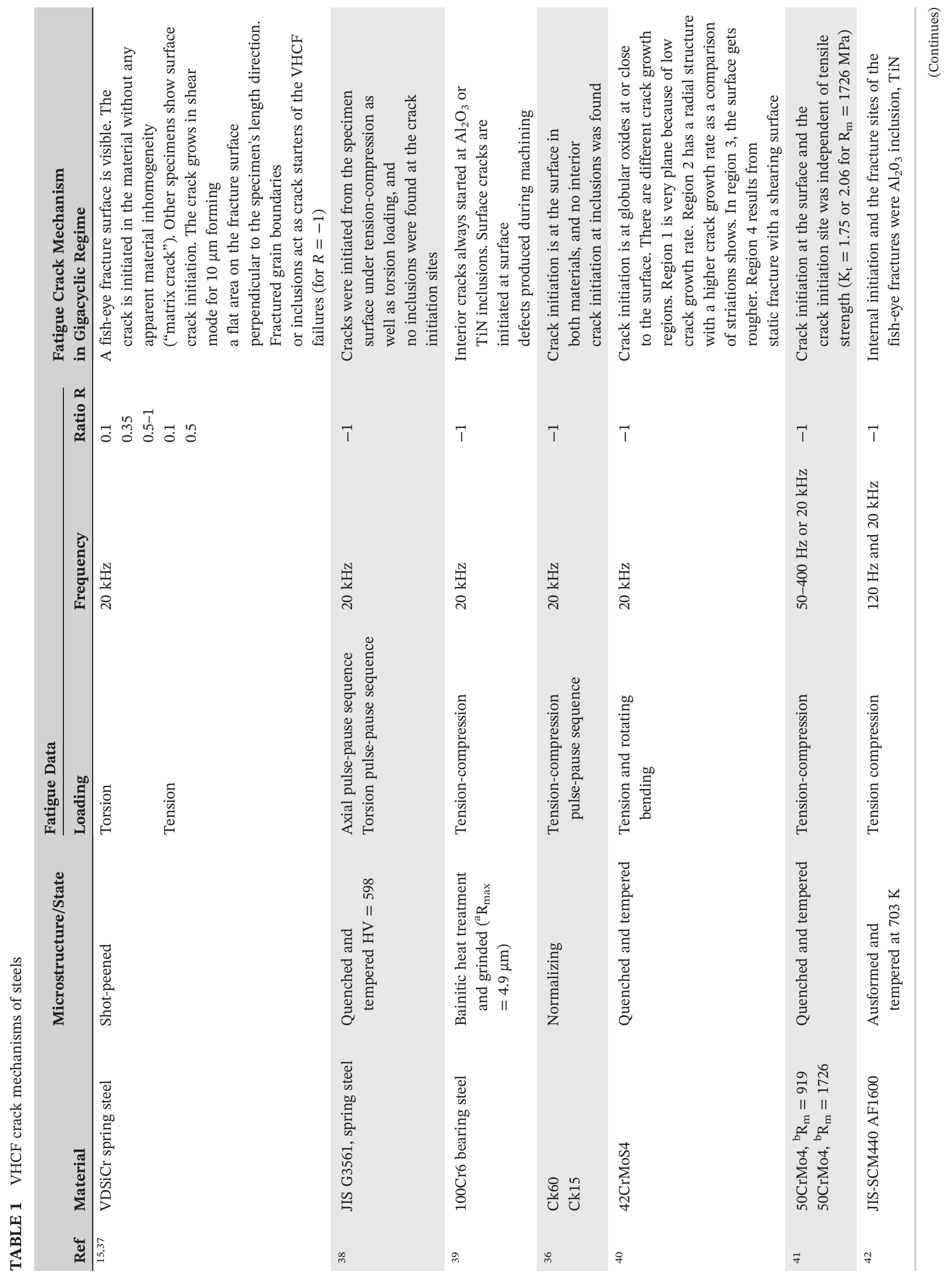




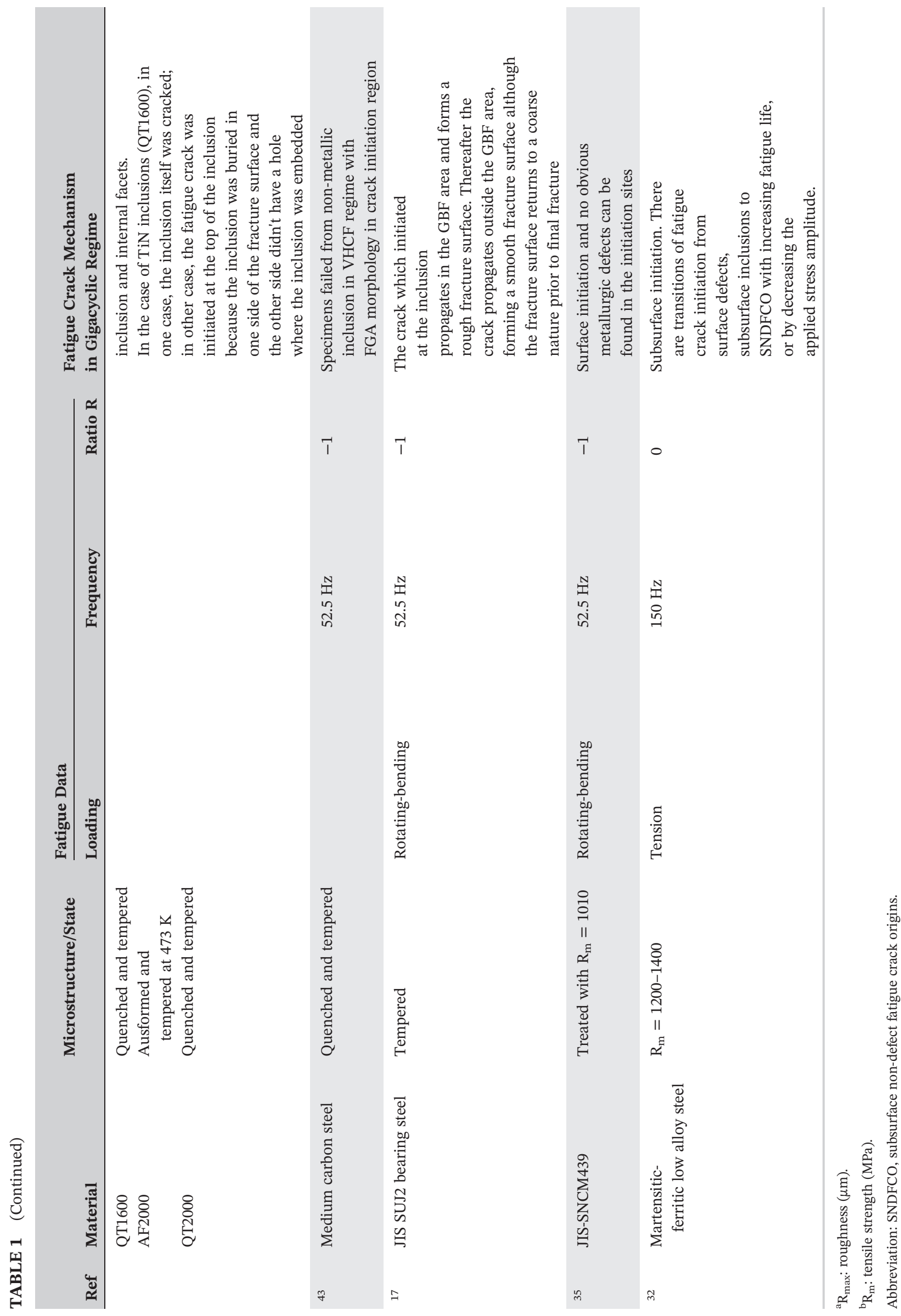




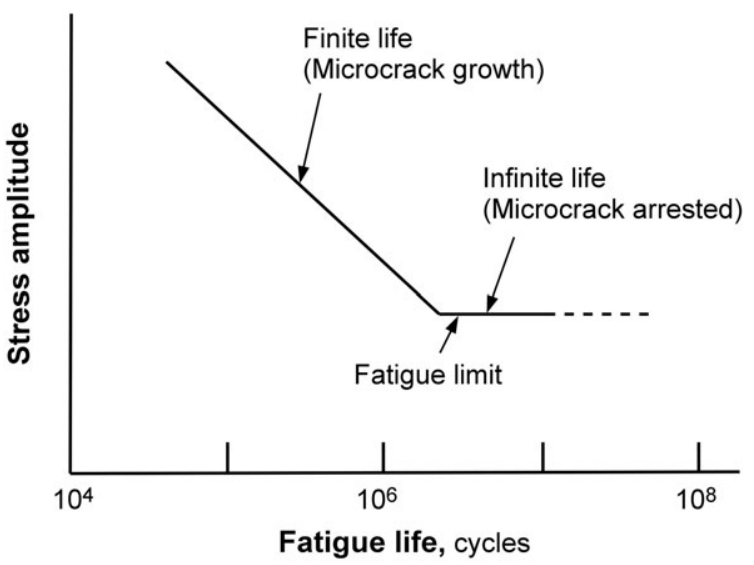

FIGURE 3 Traditional concept of $S$ - $N$ curve according to ASTM and AFNOR standards ${ }^{44-46}$

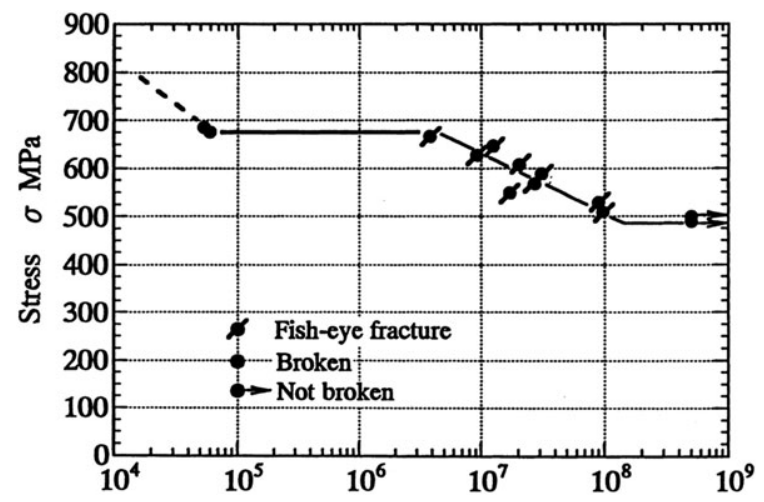

FIGURE 4 Step-wise $S$ - $N$ curve of quenched and tempered $0.46 \%$ carbon steel in tension-compression, $\mathrm{R}=-1$ at a loading frequency of $80 \mathrm{~Hz}^{48}$

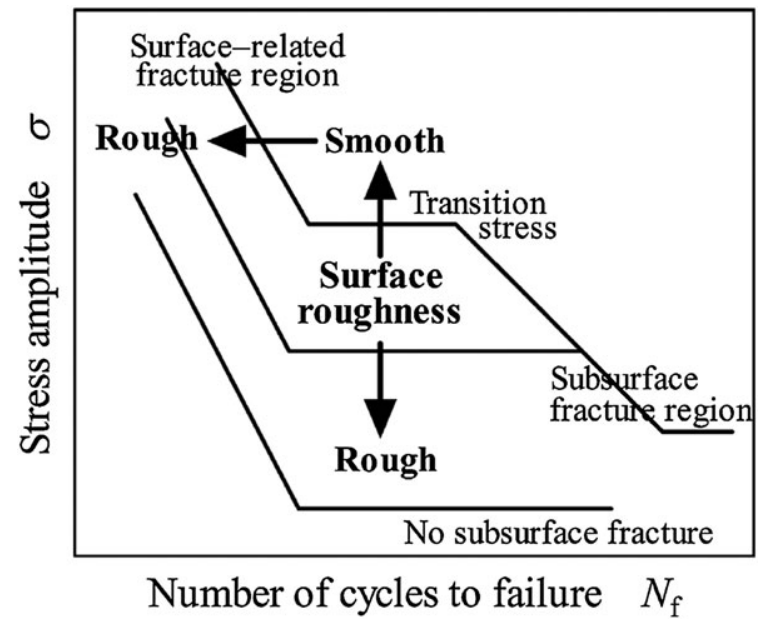

FIGURE 5 Schematic illustration showing the effects of surface roughness on S-N characteristics of high strength steel ${ }^{50}$

the specimen surface, and the $S-N$ curves present a horizontal asymptote. ${ }^{6,10,35,36,41,58}$ The difference between the fatigue strengths at $10^{6}$ and $10^{9}$ cycles is less than

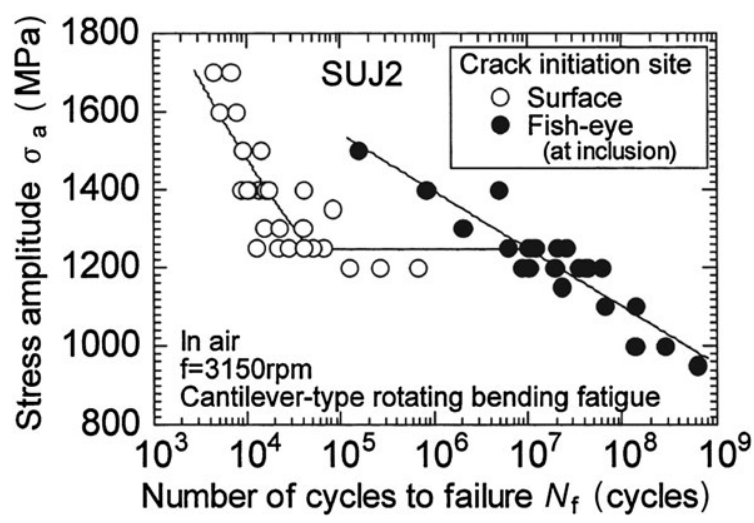

FIGURE 6 Duplex $S-N$ curve of JIS SUJ2 high strength steel under fully reversed rotating bending, at a loading frequency of $52.5 \mathrm{~Hz}^{17}$

$50 \mathrm{MPa},{ }^{2,36}$ that is within the typical scatter band of the experimental fatigue data. An example of such an $S-N$ curve is shown in Figure 7.

\section{3 | EFFECT OF MICROSTRUCTURAL AND MECHANICAL FEATURES ON THE VHCF RESISTANCE OF STEELS}

In this section, the influence of the microstructural characteristics including metallurgical phases and inclusions as well as mechanical properties, namely tensile strength and residual stresses on the VHCF, are discussed separately.

\section{1 | Influence of the metallurgical microstructure}

It is generally agreed that metallurgical microstructure greatly influences the fatigue strength of steels in the HCF domain. In general, engineers seek for a hard surface microstructure combined with a soft core to improve the fatigue strength of components in steel without decreasing their toughness. Indeed, due to the fact that crack initiation is at the surface in $\mathrm{HCF}$ regime, the surface hardness allows a higher bearable loading for a given life to crack initiation and the soft core decreases the crack propagation rate. However, in VHCF regime, generally, crack initiation on most of the structural steels occurs in the core. For the ultrasonic laboratory tests, the high loading frequency complicates this simple interpretation. Actually, from the experimental observations, it appears that specimens loaded at $20 \mathrm{kHz}$ could exhibit a temperature rise, and consequently, this may influence the stability of the different phases of the microstructure. ${ }^{5}$ For the martensitic steels and carbon steels, the increase of 
TABLE 2 Influence of the maximum tensile strength, $\mathrm{R}_{\mathrm{m}}$, on the gigacycle fatigue strength amplitude of steels in tension-compression $(R=-1)$ under a loading frequency of $20 \mathrm{kHz}$

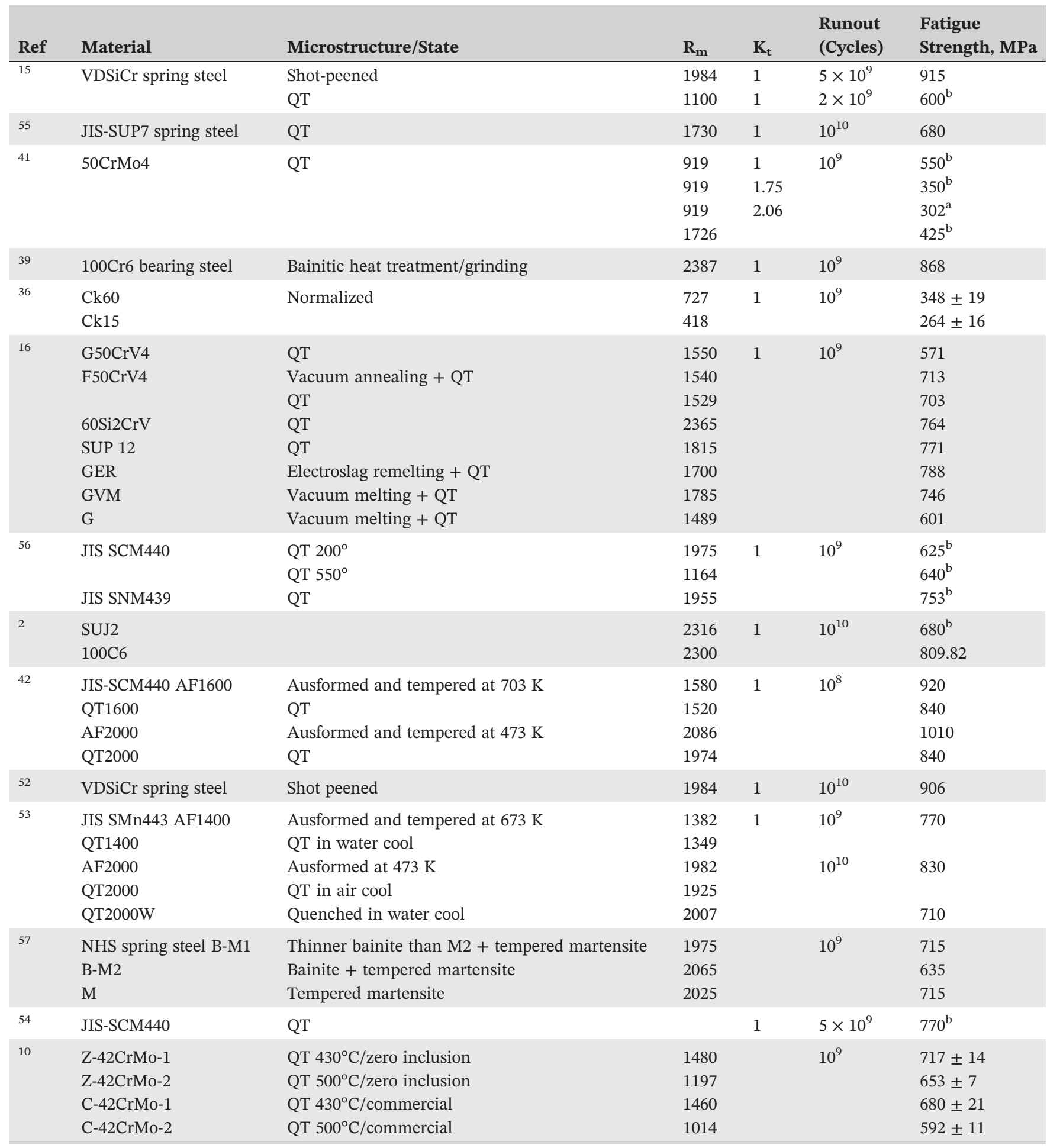

${ }^{\mathrm{a} C a l c u l a t e d}$ with stair-case method from articles data.

${ }^{\mathrm{b}}$ The maximum stress amplitude below which no specimens failed at the considered number of cycles.

Abbreviation: QT, quenched and tempered.

temperature due to the frequency is negligible with an engineering point of view (less than $80^{\circ} \mathrm{C}$ ). Nevertheless, in stainless steels, the temperature can reach $235^{\circ} \mathrm{C}$ due to the austenite to martensite transformation. ${ }^{5}$ That is why the case of stainless steels would not be treated hereafter; this paper focuses on non-stainless steels only.

Many studies indicate that the microstructure has a significant effect on the VHCF behavior of steels. ${ }^{6,51,58,59}$ 


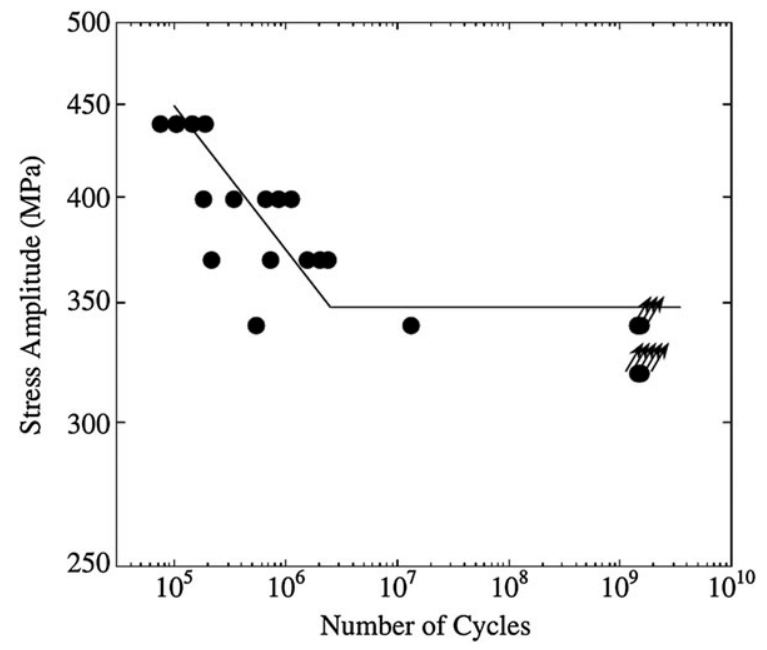

FIGURE $7 \quad S$ - $N$ curve of Ck60 steel in tension-compression $(\mathrm{R}=-1)$ at a loading frequency of $20 \mathrm{kHz}^{36}$

For example, the quenched and tempered JIS SUJ2 steel shows different $S$ - $N$ curves corresponding to 2 types of heat treatment in air and in vacuum atmosphere. ${ }^{51}$ It can be seen in Figure 8 that decarburization which occurred by the heat treatment processed in air influences greatly the fatigue life.

For ferrite and pearlite microstructures, the ferrite as bcc-material exhibits pronounced strain rate sensitivity at ambient temperatures. ${ }^{6}$ The investigations on 3 plain steels C15E, C45E, and C60E by Bach et al ${ }^{59}$ with different pearlite/ferrite ratios show that fatigue life diagrams are shifted to higher lives with increasing pearlite content (Figure 9).

Contrary to what has been proposed by Bathias, ${ }^{5}$ the microstructure can be transformed under loading even if

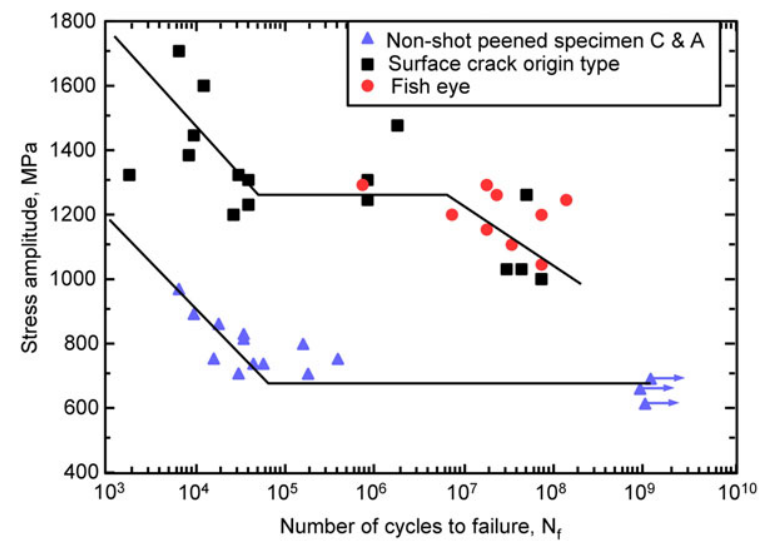

FIGURE 8 The $S$ - $N$ curves for JIS SUJ2 which were heat treated in vacuum (dark square and red circle marks) and in air (blue triangle marks) under rotating bending fatigue at a loading frequency of $52.5 \mathrm{~Hz}^{51}$ [Colour figure can be viewed at wileyonlinelibrary.com]

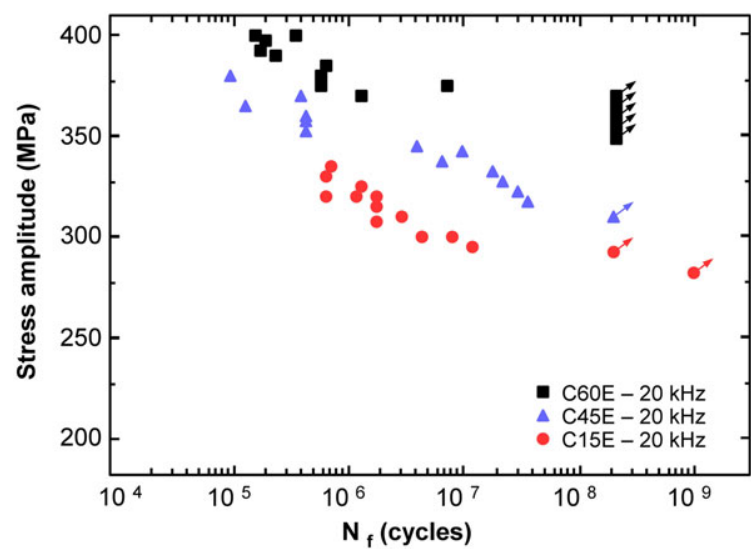

FIGURE 9 Effect of the increase of pearlite content from C15E to C60E plain steels on the $\mathrm{S}-\mathrm{N}$ diagrams in tension-compression $(\mathrm{R}=-1)$ at a loading frequency of $20 \mathrm{kHz}^{59}$ [Colour figure can be viewed at wileyonlinelibrary.com]

the temperature does not exceed $60^{\circ} \mathrm{C} .{ }^{60}$ Indeed, in bainite/martensite multiphase steels for example, it was reported in Gao et $\mathrm{al}^{31}$ that the blocky retained austenite transforms easily to martensite due to local plastic deformation under cyclic loading, which is apt to induce the formation of micro-cracks. Zhao et $\mathrm{al}^{25}$ pointed out that large plastic deformation occurred within the bainite laths, leading to "debonding" from the adjacent martensite. Consequently, the crack initiated at grain boundaries between large bainite laths and martensite. This means that the microstructure instability under cyclic loading is not only governed by temperature.

However, the reader has to keep in mind that the temperature rise in gigacycle fatigue under ultrasonic loading can be induced by many phenomena. Indeed, dissipative sources in metallic alloys are numerous: micro-plastic deformations, dislocation movements, internal friction, precipitates, plasticity-induced phase transformations, etc. An interesting paper has been published by Mareau et al in 2012. ${ }^{61}$ These authors assumed that 2 different mechanisms are responsible for heat dissipation under cyclic loading: the oscillation of pinned dislocations defined as an anelastic mechanism and the viscoplastic slip of dislocations considered as an inelastic mechanism. The dissipation is not grain size sensitive in the anelastic regime but decreases with decreasing grain size in the second regime, as expected from experimental data. Predicted results demonstrate the key role of dispersion of grain size and orientation. Additional studies are needed to more deeply investigate the relation between self-heating and the gigacycle fatigue strength of steels. Overall, the temperature rising in ultrasonic fatigue has a large effect on the $S-N$ curve shape and on the scatter. ${ }^{62}$ 


\subsection{Influence of inclusions size, type, and depth}

In VHCF regime, high-strength steels with a maximum tensile strength typically exceeding $1100 \mathrm{MPa}$ show an internally originating fatigue failure, ie, fish-eye feature. Murakami et $\mathrm{al}^{63}$ found that the median fatigue strength at $10^{7}$ cycles under fully reversed loading in high strength steels depends on the Vickers hardness of the matrix, HV, and the inclusion size as follows:

$$
\sigma_{w}^{\prime}=\frac{1.56(H V+120)}{\sqrt{\text { area }}^{1 / 6}}
$$

where $\mathrm{HV}$ is in $\mathrm{kgf} / \mathrm{mm}^{2}$ and $\sqrt{\text { area }}$ (in $\mu \mathrm{m}$ ) is the inclusion size at the fracture origin measured on the plane perpendicular to the maximum principal stress. Murakami shows that reducing the size and width of the distribution of inclusions, defects, and in-homogeneities is very important to improve the VHCF strength of high strength steels. ${ }^{64}$ Even though one thinks reinforcement mechanical treatments which focus on the improvement of the properties of the material (as shot peening do) could enhance VHCF strength, they would be sometimes insignificant in the case of high strength steels. ${ }^{9,64}$

Indeed, several researches show that the expected service life depends more on the FGA size around inclusions, when it exists (see Section 2.1) than the inclusion size itself. $^{22,65}$ Indeed, the FGA size increases with the fatigue life. This should be due to the physical mechanism of FGA formation. Even if there is not a unique mechanism accepted in the VHCF community, all the authors agree that FGA formation needs time because either dislocations accumulation around inclusion ${ }^{66}$ to produce grain refinement ${ }^{67}$ or severe plastic flow at the inclusion ${ }^{68}$ assisted $^{69}$ or not by cyclic pressing needs many cycles under very low stress or strain amplitudes. Then, when the nano-grain area around the inclusion is large enough, the stress intensity factor range exceeds its threshold value and the crack propagates.

Other researches display that when the diameter of inclusion varies in rather small range, the fatigue life is dependent on the inclusion depth from the surface. ${ }^{10,18,70}$ They show that the number of cycles to failure increases with increasing the depth of inclusions. Yang et $\mathrm{al}^{10}$ show that the VHCF strength of a material with zero inclusion is raised and the reliability is improved (ie, no fatigue fracture occurs for number of cycles between $2 \times 10^{6}$ and $10^{9}$ cycles) in comparison with the commercial material. However, the treatment needed to obtain an inclusion free material is complex and expensive. ${ }^{71}$

Experimental fatigue data collected in Table 3 show that generally, the smaller the inclusion size is, the greater the VHCF strength is. That is known as the famous Kitagawa-Takahashi diagram linking the fatigue strength versus the defect size in a log-log diagram. ${ }^{73}$ Nevertheless, according to researches by Furuya et $\mathrm{al}^{72}$ on steels with inclusions, smaller than a certain size, $15 \mu \mathrm{m}$ in this case, the fatigue strength at $10^{9}$ cycles depends also on the inclusion type (ie, its chemical nature).

\section{3 | Influence of hydrogen charging}

The effect of hydrogen on surface fractures is an interesting subject especially for steels used in hydrogen energy system. Furthermore, we have seen in Section 2.1 that for high strength steels, the formation of FGA from inclusions is the origin of the internal fractures. One possible explanation of the FGA formation in the VHCF regime is attributed to the effects of hydrogen. ${ }^{74}$ Indeed, hydrogen trapped at the inclusion helps the slow crack growth that has initiated around the inclusion and consequently creates a rough fracture surface. ${ }^{56,74}$

Data collected in Table 4 display that the hydrogencharged specimens show lower fatigue strength than the uncharged ones. The degradation of the fatigue strength is as large as the hydrogen content in the material is high.

\subsection{Influence of the environment}

There are several studies in literature about the influence of the environment on the VHCF strength of aluminum and titanium alloys but only a few ones on steels. ${ }^{19}$ After the pioneer work of Endo ${ }^{76}$ and Ebara ${ }^{77}$ who showed the key role of corrosion pits that alter significantly the fatigue strength in the gigacycle regime even at ultrasonic loading frequency, Palin-Luc et al, ${ }^{78}$ then Schönbauer et al, ${ }^{79}$ and Mora et $\mathrm{al}^{80}$ have shown that corrosive aqueous environment drastically reduces the fatigue strength of steels. Cracks initiate from corrosion pits located at the specimen surface. ${ }^{77,78,80,81}$ Consequently, pits are responsible for this decrease, but this is not a pure mechanical effect. In-situ corrosion fatigue tests are significantly more aggressive than ultrasonic fatigue ones on pre-corroded specimens. ${ }^{78}$ There is a strong coupling between the environment and the cyclic loading, even at very high frequency $(20 \mathrm{kHz})$. The number of reversals seems to play a key role but not the physical time. ${ }^{80}$ A possible explanation is the coupling between cyclic microplasticity present at the specimen surface and its interaction with the corrosive media.

Knowing the effect of environment on the VHCF strength is also very important to better understand internal crack initiation. ${ }^{19}$ It is well known that crack growth rate is greater in humid air than in vacuum. ${ }^{30,82}$ This is in agreement with the observation of a very long incubation period for crack initiation which is characteristic of 
TABLE 3 Influence of the inclusion size and type on the gigacycle fatigue strength at $10^{9}$ cycles of steels in tension compression $(\mathrm{R}=-1)$ under a loading frequency of $20 \mathrm{kHz}$

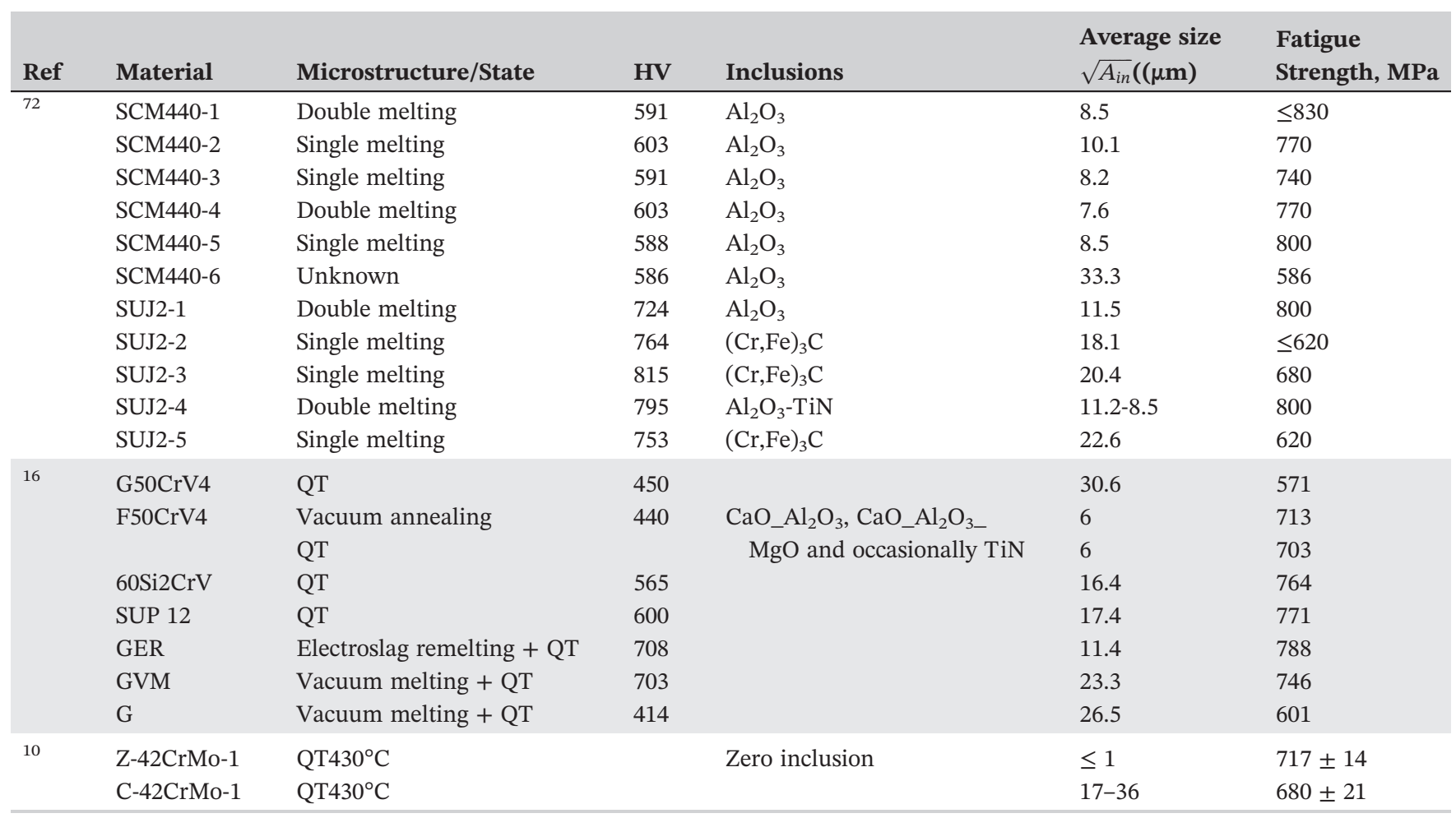

the gigacycle regime. According to Grad et al, ${ }^{20}$ the shift of the crack initiation location from surface to subsurface when the loading amplitude decreases from HCF to VHCF regime can be explained by a difference in crack growth rates and threshold of the stress intensity factor in air and in vacuum.

\subsection{Influence of the maximum tensile strength}

It's well known that there is a linear relationship between the HCF strength and the ultimate tensile strength. ${ }^{73}$ In VHCF, no such a relation is displayed in the literature. However, if we divide the collected data on smooth specimens for high strength steels and low strength steels, respectively, and focus on the data under fully reversed tension-compression at $20 \mathrm{kHz}$ (Table 2), Figure 10 corresponding to the high strength steels can be drawn.

It is important to note that for the sake of achieving comparable results, sometimes, we have needed to extract data from articles to calculate the fatigue strength according to the staircase method. When there is a large scatter in the results from literature, so that the median value of the fatigue strength could not be computed according to the staircase method, it has been estimated as the maximum stress amplitude below which no specimens failed at the considered number of cycles.
For high strength steels $(\mathrm{Rm}>1100 \mathrm{MPa})$, an empirical relationship (2) which links the median value of the VHCF strength at $10^{9}$ cycles to the maximum tensile strength, $\mathrm{Rm}$, can be brought out from the literature data as illustrated in Figure 10. However, considering the large scatter of experimental VHCF strength, it has to be pointed out that such relation has to be considered with great precautions. Indeed, because of the complexity of the mechanisms responsible for the gigacycle fatigue strength of steels, a simple relation cannot guaranty a reliable assessment of the VHCF strength. Fatigue tests are needed for safe design against gigacycle fatigue, especially when very high strength steels are considered. Indeed, for a given steel depending of the quenched and tempered conditions, a critical hardness value seems to exist above which the VHCF strength decreases. ${ }^{83}$ This seems to be due to the key role of defects (inclusions). However, Equation 2 is useful for engineers to assess the magnitude order of the VHCF resistance as proposed by Brand et al in HCF regime. ${ }^{84}$ For low strength steel $(\mathrm{Rm}<1100 \mathrm{MPa})$, such relation was not established because there are not enough experimental data.

$$
\begin{aligned}
\log \left(\sigma_{a}\right)= & 6.0461 \times 10^{-5} \\
& R_{m}+2.77 \text { for high strength steels }(\mathrm{Rm}>1100 \mathrm{MPa})
\end{aligned}
$$


TABLE 4 Influence of hydrogen charging on the gigacycle fatigue strength of steels in tension compression $(\mathrm{R}=-1)$ under a loading frequency of $20 \mathrm{kHz}$

\begin{tabular}{|c|c|c|c|c|c|c|c|c|}
\hline Ref & Material & $\begin{array}{l}\text { Microstructure/ } \\
\text { State }\end{array}$ & $\begin{array}{l}\text { Hydrogen } \\
\text { Content, ppm }\end{array}$ & $\begin{array}{l}\mathrm{C}_{\mathrm{r}}, \\
\text { ppm }\end{array}$ & $\begin{array}{l}\mathrm{C}_{\mathrm{i}}, \\
\text { ppm }\end{array}$ & $\begin{array}{l}\text { Inclusion Average } \\
\text { Size } \sqrt{A_{i n}}(\mu \mathbf{m})\end{array}$ & $\begin{array}{l}\text { Runout, } \\
\text { Cycles }\end{array}$ & $\begin{array}{l}\sigma \\
\text { MPa }\end{array}$ \\
\hline \multirow[t]{6}{*}{16} & G50CrV4 & QT & 2 & 1.34 & 0.66 & 34.3 & \multirow[t]{6}{*}{$10^{9}$} & 467 \\
\hline & F50CrV4 & QT & 2.5 & 0 & 2.5 & 6 & & 498 \\
\hline & \multirow[t]{2}{*}{$60 \mathrm{Si} 2 \mathrm{CrV}$} & \multirow[t]{2}{*}{ QT } & 3 & 0 & 3 & 11.3 & & 392 \\
\hline & & & 3.2 & 0.15 & 3.05 & 20.5 & & 483 \\
\hline & \multirow[t]{2}{*}{ SUP 12} & QT & 1 & 0.73 & 0.27 & 18 & & 628 \\
\hline & & QT & 2 & 0 & 2 & 14.1 & & 413 \\
\hline \multirow[t]{3}{*}{56} & \multirow[t]{3}{*}{ JIS SCM440 } & \multirow[t]{3}{*}{ QT $200^{\circ}$} & 2.35 & & & \multirow[t]{3}{*}{$15-78$} & \multirow[t]{3}{*}{$10^{9}$} & $380^{\mathrm{a}}$ \\
\hline & & & 1.6 & & & & & $380^{\mathrm{a}}$ \\
\hline & & & 1.47 & & & & & $460^{\mathrm{a}}$ \\
\hline \multirow{2}{*}{75} & \multirow{2}{*}{$100 \mathrm{Cr} 6$ bearing steel } & \multirow[t]{2}{*}{ Martensite } & & & 0.6 & & \multirow{2}{*}{$2 \times 10^{9}$} & 926 \\
\hline & & & & & 3 & & & 531 \\
\hline
\end{tabular}

$\mathrm{C}_{\mathrm{r}}$ : non-diffusible hydrogen in the specimen.

$\mathrm{C}_{\mathrm{i}}$ : hydrogen being charged into the specimen.

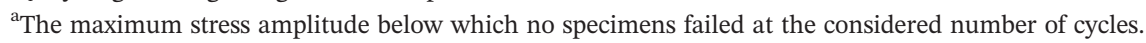

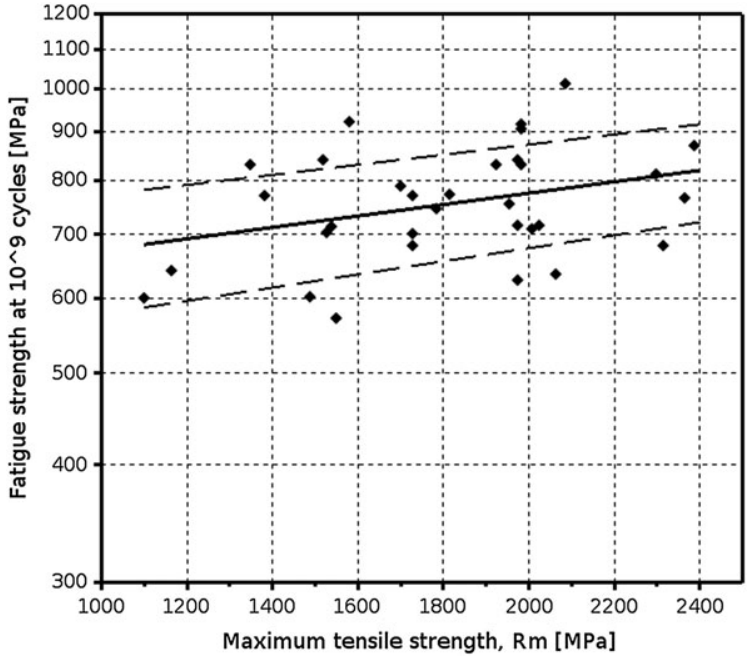

FIGURE 10 Median value of the fatigue strength at $10^{9}$ cycles (stress amplitude) vs maximum tensile strength for high strength steels, on smooth specimens under fully reversed tensioncompression at $20 \mathrm{kHz}$. The thick line is the median value, and the 2 dashed lines correspond to the boundaries of the interval containing $68 \%$ of the experimental data

\subsection{Influence of the residual stresses}

In the HCF regime, residual stresses are seen as mean stresses with the same global effect as described by the Haigh diagram: a positive mean stress (tension) reduces the fatigue strength whereas a negative (compressive) one increases it. Because residual stresses are the consequence of local strain incompatibilities, a good compromise has to be found between compressive and tensile residual stresses in volume (a local compressive stress is balanced elsewhere in the specimen or component with tensile residual stresses) ${ }^{85,86}$ Consequently, engineers try usually to create compressive surface residual stresses which mitigate the loading stress at the surface and delay fatigue crack initiation or increase the bearable stress amplitude. That is why, among others reasons, different surface thermal or mechanical treatments are suggested to improve the HCF strength of components. ${ }^{87}$ In VHCF regime, the influence of residual stresses on the fatigue strength is not obvious because crack initiation does not usually occur at the surface, especially for high strength steels under axial loading. ${ }^{9,14,88}$

Generally, residual stresses are unstable during cyclic loading, one talk about relaxation of the residual stresses. ${ }^{89,90}$ For instance, in the case of shot peened spring steel VDSiCr under torsion loading, there is an important drop of the compression residual stresses after VHCF loading. ${ }^{37}$ One notes that for the same residual stresses before loading, the decrease of the compressive residual stresses after torsion loading is in descending order, more significant for a loading ratio $R=0.5$ than for $R=0.35$ or $R=0.1$. Thereby, the VHCF strength is the highest in the case of the minimum decrease of 
residual stresses after loading. Nevertheless, in the case of tension there is a slight rising of the compressive residual stresses after fatigue loading. ${ }^{15}$

Overall, more thorough work needs to be done to conclude about the stability or instability of residual stresses under loading with low amplitude and their influence on the VHCF strength of steels. Furthermore, residual stresses are not uniaxial but multiaxial and modify the distribution of hydrostatic stress all over the component. ${ }^{91,92}$ That is why HCF strength criteria consider the hydrostatic stress to take into account the effect of residual stresses. But according to the authors' knowledge, there is no study in VHCF regime considering both the multiaxial nature of residual stresses and their heterogeneous distribution in all the specimen (or component), including the presence of non-metallic inclusion, if any. Additional studies should be done in this way for a better understanding of the effect of residual stresses in VHCF.

\section{4 | EFFECT OF THE LOADING CONDITIONS ON THE VHCF RESISTANCE OF STEELS}

Loading conditions for fatigue tests in $\mathrm{HCF}$ regime include the loading type and the loading ratio. When dealing with the VHCF regime, the discussion is enlarged about the influence of the loading frequency and the testing techniques. Indeed, there is a variety of testing techniques in the literature in VHCF that could influence the fatigue results as will be shown hereafter.

\section{1 | Influence of the loading frequency and risk volume (or highly stressed volume)}

Recent researches have suggested that the influence of the loading frequency when there is "fish-eye" formation should be coupled with size effect. Actually, the size of specimens that are used with ultrasonic testing devices are different with those on conventional ones. Indeed, the specimens usually used in ultrasonic fatigue testing are smaller than in conventional fatigue testing. A typical ultrasonic fatigue test specimen is hourglass-shaped with a diameter of $3 \mathrm{~mm}$ at its minimum cross section, while conventional fatigue testing frequently uses specimens with diameter between 6 and $12 \mathrm{~mm} .^{54}$ The size of the region where the higher stress acts in a fatigue test specimen is what we called the "risk volume" or the "highly stressed volume." Different "risk volumes" can influence the probability to have critical inclusions with regard to the fatigue crack initiation. One can note that there is a good match between ultrasonic and conventional data when the risk volume is the same (Figure 11). ${ }^{41,54,93} \mathrm{Nev}$ ertheless, Figure 12 depicts different fatigue strengths for different risk volumes when ultrasonic frequency tests are considered. Sun et $\mathrm{al}^{94}$ proposed a method based on statistical analysis to estimate the fatigue life of large specimens from the experimental data of small specimens.

It has been shown that the inclusion size at the fisheye fracture origins increased in proportion to increased risk volume, suggesting that this enlargement of inclusion sizes is what causes the degradation of fatigue strength. ${ }^{74}$

For specimens with an hourglass shape and a minimum diameter of $3 \mathrm{~mm}$, the shape of the $S-N$ curves depends only on the inclusion size. ${ }^{95}$ A modified $S-N$ diagram where stress amplitudes are normalized by fatigue strengths estimated according to Equation 1 is proposed in this case (Figure 13). Hence, when the risk volume is the same, there is no frequency effect on the fatigue strength. ${ }^{2,41,42,55,56}$ That is why Paolino et $\mathrm{al}^{96}$ have proposed a new specimen geometry (named Gaussian

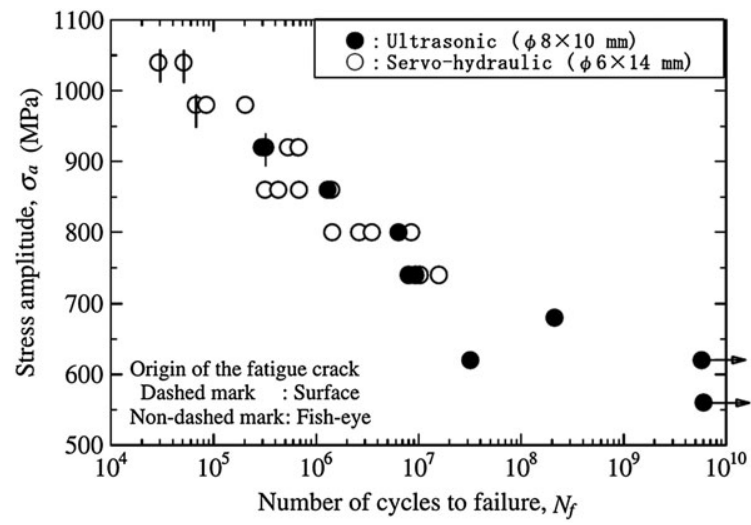

FIGURE 11 Fatigue test results for specimens of JIS-SCM440 with almost equal risk volumes in tension-compression $(\mathrm{R}=-1)$ at a loading frequency of $20 \mathrm{kHz}$ (ultrasonic) and $20 \mathrm{~Hz}$ (servohydraulic $)^{54}$

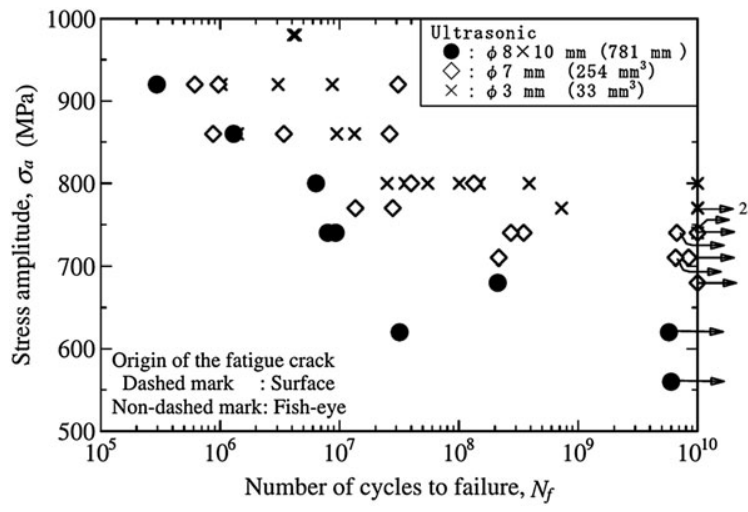

FIGURE 12 Ultrasonic fatigue test results for specimens of JISSCM440 with various risk volumes in tension-compression $(\mathrm{R}=-1)$ at a loading frequency of $20 \mathrm{kHz}^{54}$ 


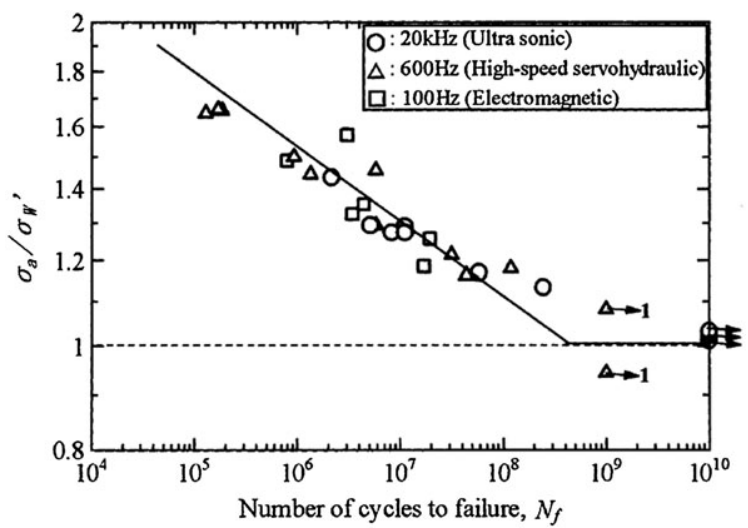

FIGURE 13 Modified $S$ - $N$ diagram where stress amplitudes are normalized by the fatigue limit estimated by Murakami's Equation 1 for JIS SNCM439 in tension-compression, $\mathrm{R}=-1^{95}$

specimen) with larger risk volume to study the effect of the highly stressed volume in gigacycle fatigue regime with ultrasonic fatigue testing machines.

As said before, in general, smooth specimens frequently used for carrying out ultrasonic fatigue tests are of the hourglass type with a diameter of $3 \mathrm{~mm}$ at the $\mathrm{min}$ imum section.

Therefore, in order to find a correlation between the diameter of the specimen and the fatigue strength at different frequency tests, we consider the ultrasonic fatigue strength and the diameter of $3 \mathrm{~mm}$ as reference. Many studies display a difference between $S-N$ curves at $20 \mathrm{kHz}$ and at conventional frequency (ie, between 20 and $400 \mathrm{~Hz}$ ). Let us now suppose that there is a scale effect in that case which can affect the curve. Indeed, it is well established that when the specimen size increases, the fatigue strength decreases. So, if we make the assumption that the fatigue strength is inversely proportional to the specimen diameter, we could determine the correlation between the ultrasonic fatigue strength and the conventional one. Such a coefficient can reduce the gap between the 2 curves when tests are carried out with different specimen diameters at different frequencies, as follows:

$$
\frac{\sigma_{s, \text { con }}(N)}{\sigma_{s, u l t}(N)}=\left(\frac{a}{d}\right)
$$

where, $\sigma_{s, \text { con }}$ is the conventional fatigue strength amplitude for a given number of cycles, $N$, under conventional frequency on a classic testing machine and $\sigma_{s, \text { ult }}$ is the ultrasonic fatigue strength amplitude (at $20 \mathrm{kHz}$ ); " $d$ " is the specimen diameter and " $a$ " is the correlation coefficient. For each number of cycles, the fatigue strength at $20 \mathrm{kHz}$ can thus be assessed from fatigue tests carried out a usual frequency.
This method has been applied to take into account the effect of the highly stressed volume on the fatigue data extracted from. ${ }^{55}$ Figure 14 shows that the various points of the conventional $S-N$ curve move in the vertical direction to fit the ultrasonic fatigue curve. The fatigue test specimens were of hourglass type with a diameter of 3 and $6 \mathrm{~mm}$ at the minimum cross section corresponding, respectively, to tests at $20 \mathrm{kHz}$ with an ultrasonic testing machine and at $120 \mathrm{~Hz}$ with an electromagnetic one. The same method applied to the fatigue data in Pyttel et $\mathrm{al}^{40}$ gives the same conclusion (Figure 15). This shows that the size effect has to be taken into account when comparing fatigue tests results obtained under different loading frequencies.

Data summarized in Table 5 show that generally, by eliminating the other parameters that could affect the VHCF strength of steels (such as: size effect, increase of temperature, instability of microstructure, and environment), the loading frequency has no effect in the case of high strength steels. Nevertheless, for low strength steels, the fatigue "limit" increases with an increase of the

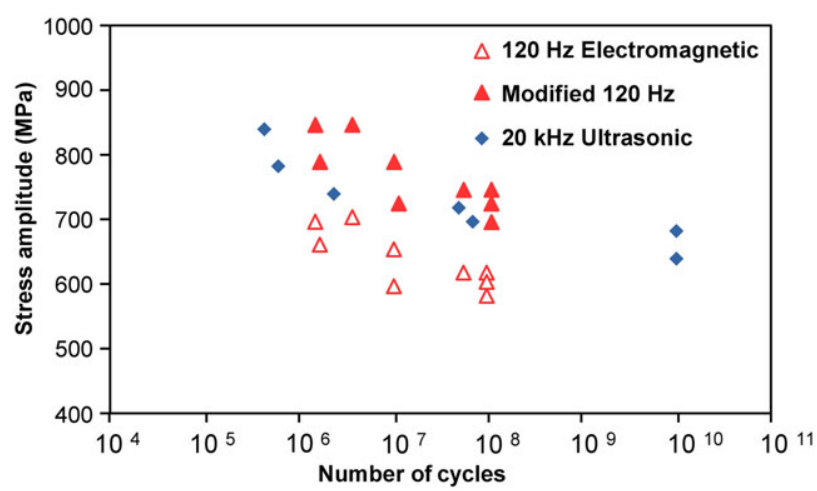

FIGURE $14 S-N$ diagrams for JIS-SUP7 spring steel in tension compression loading $(\mathrm{R}=-1)$ from Furuya and Matsuoka ${ }^{55}$ [Colour figure can be viewed at wileyonlinelibrary.com]

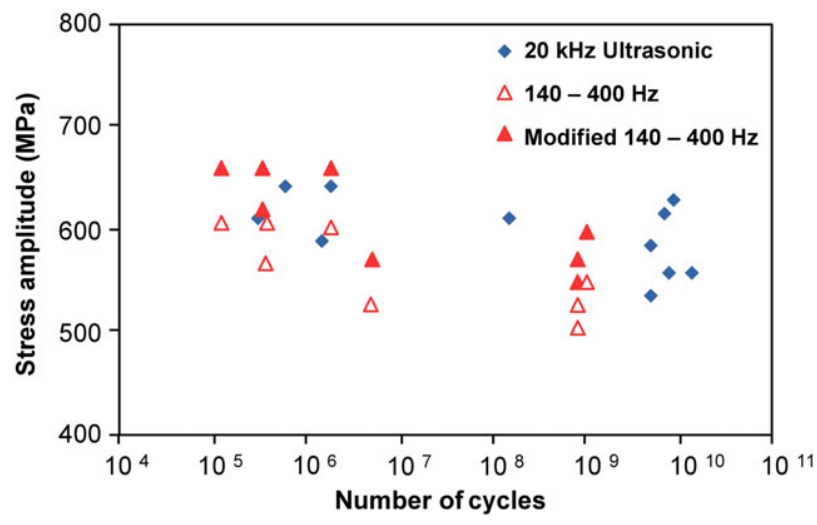

FIGURE $15 S$ - $N$ diagrams for $42 \mathrm{CrMoS} 4$ steel in tension compression loading $(\mathrm{R}=-1)$ from Pyttel et $\mathrm{al}^{40}$ [Colour figure can be viewed at wileyonlinelibrary.com] 


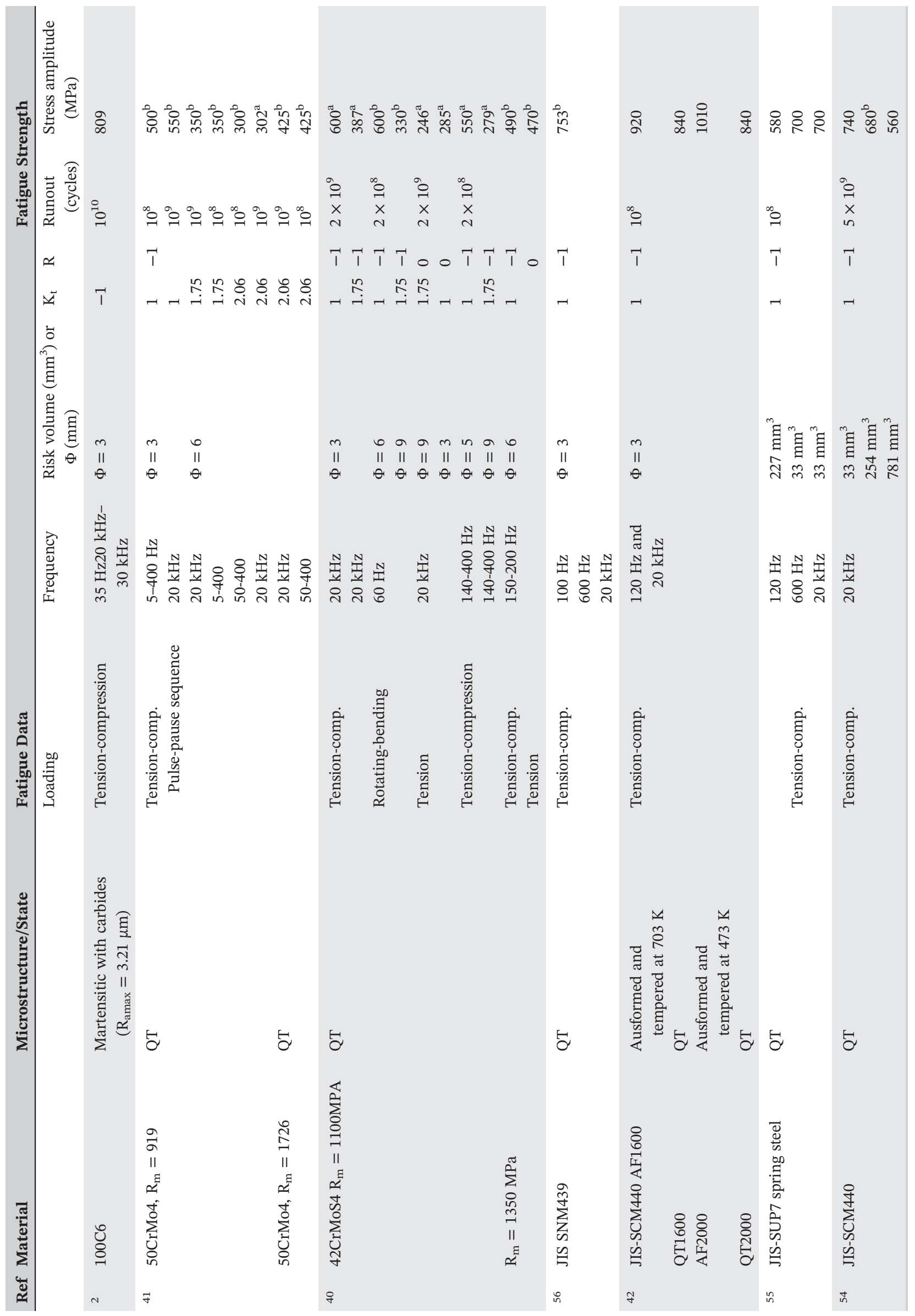




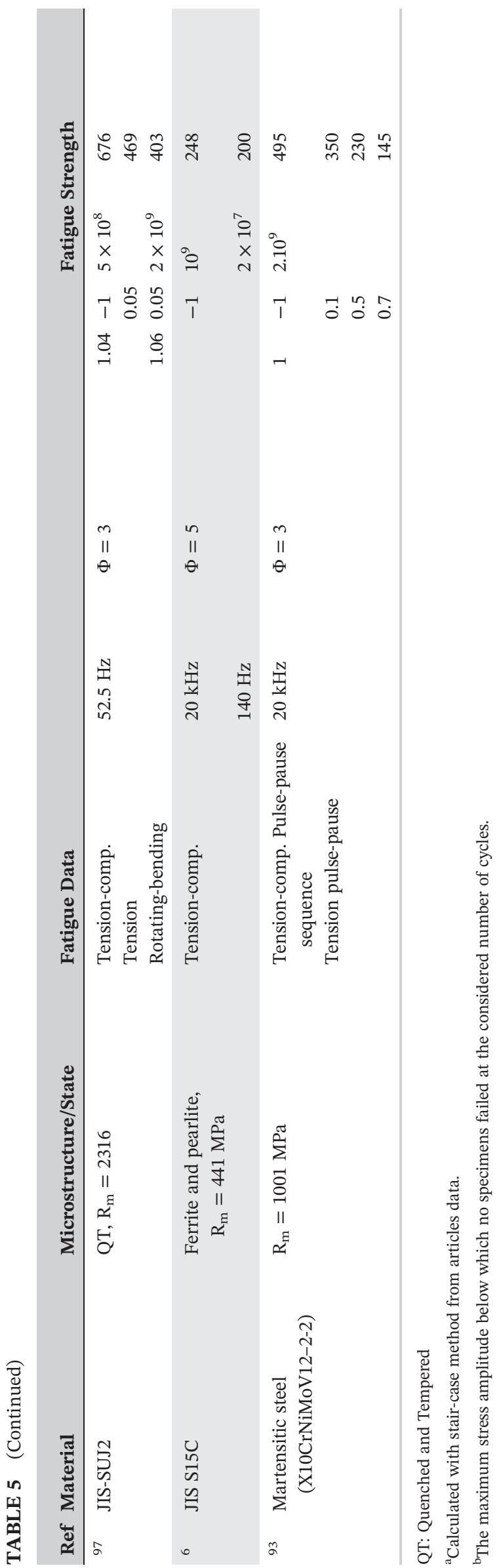

testing frequency ${ }^{6,41}$ for smooth specimens (Figure 16), but no influence is observed for notched ones (Figure 17).

A possible explanation can be found in Takeuchi et $\mathrm{al}^{98}$ : "considering that generally, dislocation velocities are far slower than sonic speed ${ }^{99}$ and that initiation and propagation of fatigue cracks are closely related to local plastic deformations, it can be easily imagined that plastic deformation cannot follow reacting to the loading at high frequency and therefore results in fatigue property changes. Indeed, Lee et al show that with increasing the strain rate, the number of dislocations inside the cell walls increases and the size of the individual dislocation cells decreases. An increased dislocation density, which increases the degree of dislocation tangling, reduces the mobility of the dislocations and therefore enhances the resistance of the material to cyclic plastic deformation ${ }^{100}$."

A similar phenomenon has also been observed under monotonic high-speed tensile tests. ${ }^{6}$ When the tensile speed is increased, the yield stress and tensile strength tend to also be higher in this case. Secondly, the influence of the frequency is small in the case of the notched specimens because the plastic zone is limited to the stress concentration zone and fracture is the result of stress concentration at the notch root.

The effect of frequency is bound to the effect of strain rate on the fatigue strength. In VHCF regime, the high strain rate and the induced rise of temperature during tests could conduct to dynamic strain aging phenomena in sensitive steels. Indeed, Torabian et $\mathrm{al}^{101}$ showed that for a ferritic-martensitic steel, strain aging, which resulted from the high temperature during ultrasonic tests, strengthens the surrounding ferrite matrix. Therefore, the plastic zone at the crack tip is smaller and requires

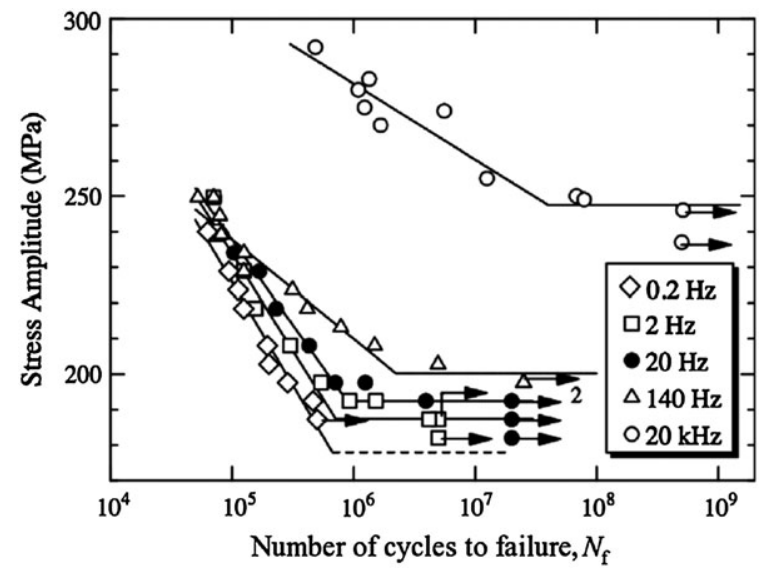

FIGURE $16 S$ - $N$ diagram of JIS S15C steel, Rm $=441 \mathrm{MPa}$, under several loading frequencies in tension compression with $\mathrm{R}=-1$ (all the specimens have a tested portion with a same diameter of $5 \mathrm{~mm})^{6}$ 
FIGURE $17 \quad S$ - $N$ diagram of smooth specimens (diameter of $3 \mathrm{~mm}$ ) and notched specimens $(\mathrm{Kt}=1.75$, diameter of $6 \mathrm{~mm}$ ) with polished surface of 50CrMo4 steel, $\mathrm{Rm}=919 \mathrm{MPa}$, in tensioncompression, $\mathrm{R}=-1^{41}$ [Colour figure can be viewed at wileyonlinelibrary.com]

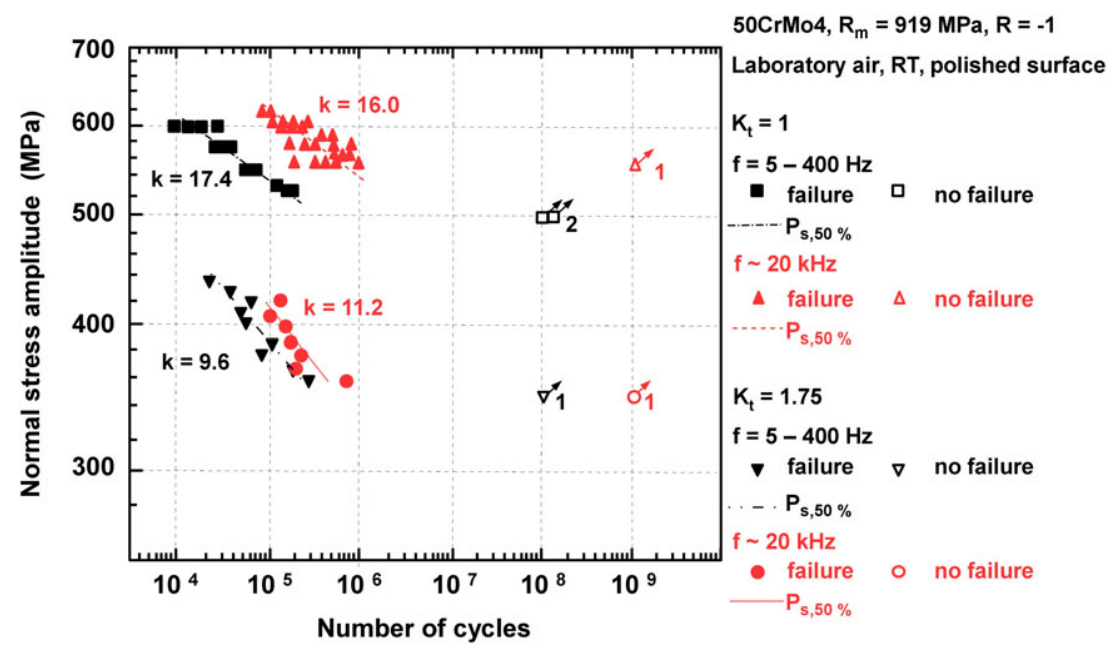

higher stresses to propagate leading to an increase in the fatigue life for a given stress amplitude.

\section{2 | Influence of load ratio and loading type}

Data summarized in Table 5 show that several investigations about the normal mean stress sensitivity in the VHCF regime already exist for axial and rotational loading types. ${ }^{15,93}$ Generally, the $S-N$ curves of steels are shifted towards lower stress amplitudes with increasing the load ratio independently of the loading type. ${ }^{102}$ An example is depicted in Figure 18. This is described in the Haigh diagram by the Goodman line or the Gerber parabola like in HCF regime (Figure 19).

The influence of the loading type (tension, bending, etc.) on the fatigue strength is connected to the stress gradient effect; consequently, the highly stressed volume is reduced when the stress state is not homogenous. ${ }^{103}$
Figure 20 shows a schematic illustration of the control volume depending on the loading conditions. ${ }^{97}$ Specimens with identical center sections, where stress amplitudes are highest and fatigue cracks initiate, display different highly stressed volumes under torsion and axial loading. Indeed, torsion loading forms a gradient of shear stress over the cross section with maximum stress at the surface and vanishing stress in the center. The stress gradient yields a much smaller highly stressed volume compared with cyclic tension. Consequently, the probability to find a defect is reduced with the control volume reduction.

This explains why Akiniwa et $\mathrm{al}^{38}$ reported larger scatter for ultrasonic torsional fatigue tests of spring steel than that of ultrasonic tension-compression fatigue tests. The same remark was mentioned in Shimamura et $\mathrm{al}^{58}$ for the carburized SCM420H steel. We can conclude that the effects of load ratio and loading type in the VHCF regime are the same as in $\mathrm{HCF}$ apart from all the other involved parameters.
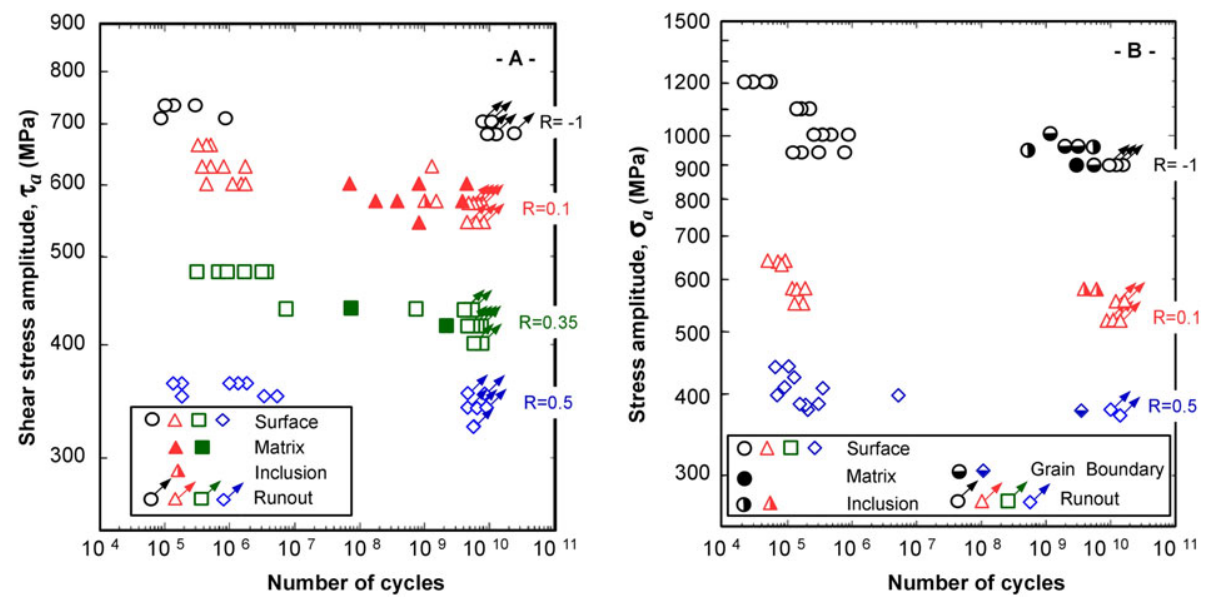

FIGURE $18 S$ - $N$ data of shot peened VDSiCr spring steel, ${ }^{15}(\mathrm{~A})$ under torsion $(\mathrm{R}=-1)$, (B) under tension $(\mathrm{R}=-1)[$ Colour figure can be viewed at wileyonlinelibrary.com] 


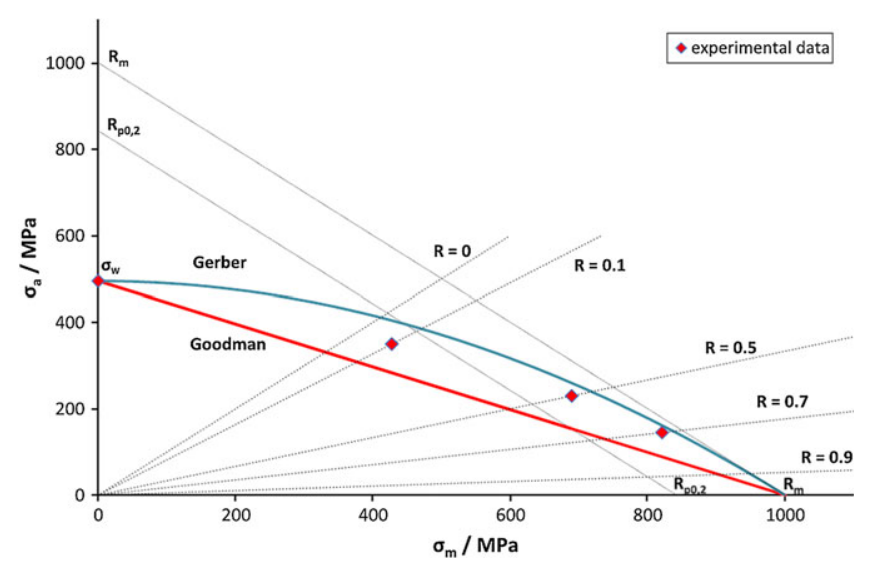

FIGURE 19 Influence of the loading ratio, R, in VHCF regime on martensitic steel (X10CrNiMo12-2-2) ${ }^{93}$ [Colour figure can be viewed at wileyonlinelibrary.com]

\subsection{Influence of the testing techniques}

Testing devices are based on different operating principles, and the controlled parameters are not the same: force for conventional techniques (in HCF regime) and displacement with ultrasonic ones. In VHCF regime, one single test in the range of $10^{10}$ cycles would take 17 years with a conventional $20 \mathrm{~Hz}$ servohydraulic machine; however, using a $20 \mathrm{kHz}$ ultrasonic fatigue testing device shortens this testing time to less than a week. ${ }^{104}$ Furthermore, with the ultrasonic fatigue testing technique, the specimen is not just prone to a cyclic stressing cycles obtained by displacement of the machine's horn, but the specimen itself is placed into resonance. ${ }^{2,82,105}$

Relevant sum up of the progress of ultrasonic fatigue testing machines and devices in the recent 30 years in order to test specimens in VHCF regime is given in Bathias. ${ }^{105}$ Exhaustive description of the different test devices in VHCF under tension-compression and rotating bending loadings under constant or variable amplitudes exists in many other articles. ${ }^{21,37,41,58,106,107}$

Except the test frequency, the main differences between conventional and ultrasonic devices are the different specimens shape and the possibility of temperature rise under ultrasonic loading. Indeed, the different smooth specimen shapes corresponding to the different test devices could lead to different test results. Actually, as displayed previously, the size effect has a significant influence on the fatigue test results (Section 4.1). The tests with larger highly stressed volumes exhibit the lower fatigue strength. This is in agreement with the statistics of extreme: there is a higher probability to find a defect (inclusion) in a larger volume. ${ }^{73}$

To avoid temperature rise during ultrasonic fatigue tests, there are 2 different techniques in the literature: either specimens are cooled by dry pressured air or any other coolant (water, oil, etc.), or tests are carried out with the pulse and pause technique. Thereby, pulse-lengths are typically between 25 and $100 \mathrm{~ms}$ (500-2000 cycles), and pauses can vary between 25 and $1000 \mathrm{~ms}$ and depend on the damping of the specimen material. ${ }^{82}$

To our knowledge, there is no study which compares the influence of these 2 techniques on the VHCF strength of the same steel. However, one can find in the literature ${ }^{2,5,53,98}$ that the temperature rise indicates the development of plastic strains in some zones of the specimen in quenched and tempered steels. Such plastic deformation appeared to be a necessary precursor of rapid ageing in this case. If cyclic stressing was stopped just after a temperature peak, ageing continued during the period of resting. ${ }^{108}$ Thereby, for the sensitive materials to dynamic strain aging, careful considerations are necessary when the results are obtained by using an ultrasonic

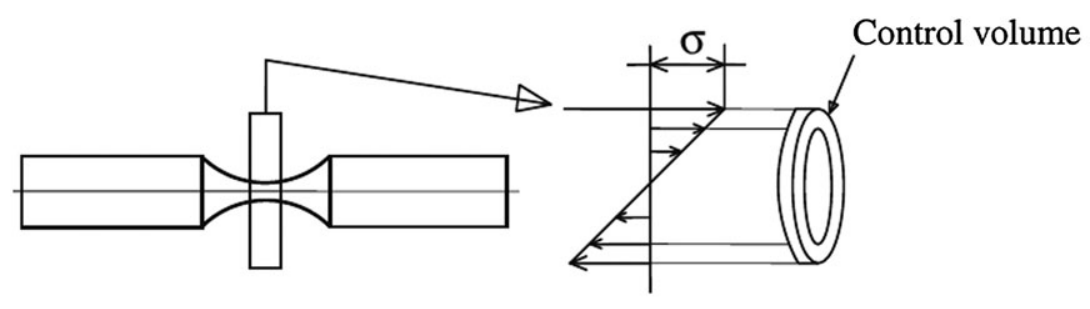

(A) Rotating bending

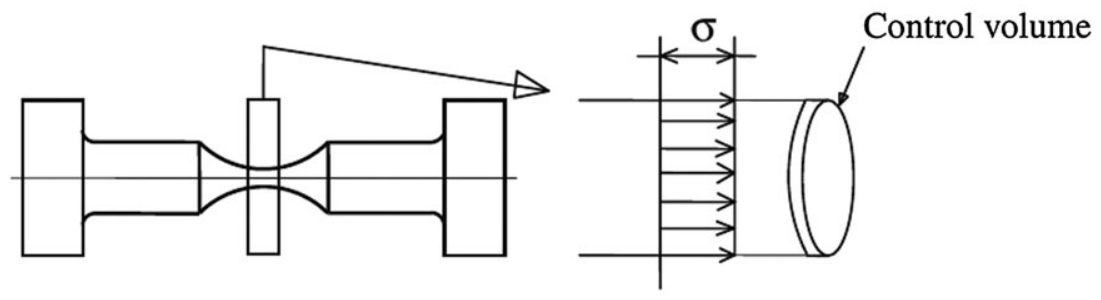

(B) Axial loading

FIGURE 20 Schematic illustration of the control volume depending on loading conditions, note that the control volume for rotating bending is much smaller than that for axial loading ${ }^{97}$ 
testing machine even with pulse and pause technique. The question of a possible sensitivity of the material to cyclic creep should be studied too under positive mean stress for the same reason.

\section{5 | CONCLUSIONS AND PROSPECTS}

An overview of the parameters influencing the VHCF resistance of smooth steel specimens has been proposed. The following conclusions were displayed.

- For high strength steels, fatigue cracks initiate in the core and more than $90 \%$ of the fatigue life is needed to create an FGA. The presence of the FGA is not depending on the loading frequency (conventional or ultrasonic). The stepwise or duplex $S-N$ curve typical shape depends on the loading type (tension or torsion).

- For low strength steels, fatigue crack initiation mainly occurs at the specimen surface, and the $S-N$ curves present an horizontal asymptote

- For multiphase steels, "non-inclusion induced crack initiation" has been observed, and the crack does not initiate from inclusions but within the matrix microstructure (named as SNDFCO). This shows that internal crack initiation is not only due to the presence of inclusion. This is important when trying to understand why crack initiation is shifted from surface to the core when the stress amplitude is reduced for having longer life (from HCF to VHCF regime).

- The microstructure can be transformed under cyclic loading at high frequency even if the temperature does not exceed $60^{\circ} \mathrm{C}$. This proves that microstructure instability under cyclic loading is not only governed by temperature.

- Based on the VHCF data collected in the literature, an empirical relationship has been proposed to assess the VHCF strength of high strength steels $(\mathrm{Rm}>1100 \mathrm{MPa})$ under tension $(R=-1)$ at $10^{9}$ cycles and their maximum tensile strength under quasi-static monotonic tension.

- Because residual stresses are unstable during fatigue loading, more thorough work is needed to be done to conclude about their influence on the VHCF strength of steels.

- By eliminating the other parameters which could affect the VHCF strength of steels such as size effect, increase of temperature, instability of microstructure, and environment, the loading frequency has no significant effect on the VHCF strength of high strength steels. Nevertheless, for low strength steels, the fatigue strength at $10^{9}$ cycles increases with an increase of the testing frequency.

- When comparing the VHCF strengths of high strength steels obtained either with ultrasonic or conventional loading frequency, the size effect has to be taken into account.

- Under tension the influence of the load ratio on the VHCF resistance of steels can be described by a Haigh diagram like in HCF.

- Finally, special attention should be paid to the influence or not of the pulse and pause technique to avoid temperature rising of tested specimens. There is no study which compares the influence of this technique with continuous tests on the VHCF strength of steels. This is an interesting way for future researches.

\section{ORCID}

D. Jeddi (D) http://orcid.org/0000-0002-4343-6088

T. Palin-Luc (D) http://orcid.org/0000-0002-2380-0727

\section{REFERENCES}

1. Bathias C. There is no infinite fatigue life in metallic materials. Fatigue Fract Eng Mater Struct. 1999;22:559-565.

2. Marines I, Dominguez G, Baudry G, et al. Ultrasonic fatigue tests on bearing steel AISI-SAE 52100 at frequency of 20 and 30 kHz. Int J Fatigue. 2003;25:1037-1046.

3. Stanzl-Tschegg SE. Fracture mechanisms and fracture mechanics at ultrasonic frequencies. Fatigue Fract Eng Mater Struct. 1999;22:567-579.

4. Mayer H. Recent developments in ultrasonic fatigue. Fatigue Fract Eng Mater Struct. 2016;39:3-29.

5. Bathias C. Coupling effect of plasticity, thermal dissipation and metallurgical stability in ultrasonic fatigue. Int $J$ Fatigue. 2014;60:18-22.

6. Guennec B, Ueno A, Sakai T, Takanashi M, Itabashi Y. Effect of the loading frequency on fatigue properties of JIS S15C low carbon steel and some discussions based on micro-plasticity behavior. Int J Fatigue. 2014;66:29-38.

7. Marti N, Favier V, Saintier N, Gregori F. Investigating fatigue frequency effects on single phase ductile materials. Procedia Eng. 2015;133:294-298.

8. Berger C, Eulitz KG, Heuler P, et al. Betriebsfestigkeit in Germany-an overview. Int J Fatigue. 2002;24:603-625.

9. Shiozawa K, Lu L. Very high-cycle fatigue behaviour of shotpeened high-carbon-chromium bearing steel. Fatigue Fract Eng Mater Struct. 2002;25:813-822.

10. Yang ZG, Li SX, Zhang JM, et al. The fatigue behaviors of zeroinclusion and commercial 42CrMo steels in the super-long fatigue life regime. Acta Mater. 2004;52:5235-5241. 
11. Chan KS. Roles of microstructure in fatigue crack initiation. Int J Fatigue. 2010;32:1428-1447.

12. Murakami Y, Yamashita Y. Prediction of life and scatter of fatigue failure originated at nonmetallic inclusions. Procedia Eng. 2014;74:6-11.

13. Sakai T, Sato Y, Oguma N. Characteristics S-N properties of high-carbon-chromium-bearing steel under axial loading in long-life fatigue. Fatigue Fract Eng Mater Struct. 2002;25:765773.

14. Nie B, Zhang Z, Zhao Z, Zhong Q. Very high cycle fatigue behavior of shot-peened $3 \mathrm{Cr} 13$ high strength spring steel. Mater Des. 2013;50:503-508.

15. Mayer H, Schuller R, Karr U, et al. Mean stress sensitivity and crack initiation mechanisms of spring steel for torsional and axial VHCF loading. Int J Fatigue. 2016;93:309-317.

16. Li YD, Chen SM, Liu YB, et al. The characteristics of granularbright facet in hydrogen pre-charged and uncharged high strength steels in the very high cycle fatigue regime. $J$ Mater Sci. 2010;45:831-841.

17. Shiozawa K, Lu L, Ishihara S. S-N curve characteristics and subsurface crack initiation behaviour in ultra-long life fatigue of a high carbon-chromium bearing steel. Fatigue Fract Eng Mater Struct. 2001;24:781-790.

18. Lei Z, Hong Y, Xie J, Sun C, Zhao A. Effects of inclusion size and location on very-high-cycle fatigue behavior for high strength steels. Mater Sci Eng A. 2012;558:234-241.

19. Hong Y, Sun C. The nature and the mechanism of crack initiation and early growth for very-high-cycle fatigue of metallic materials-an overview. Theor Appl Fract Mech. 2017;92:331350.

20. Grad P, Kerscher E. Reason for the transition of fatigue crack initiation site from surface to subsurface inclusions in highstrength steels. Fatigue Fract Eng Mater Struct. 2017;40:17181730.

21. Mayer H, Schuller R, Fitzka M, Tran D, Pennings B. Very high cycle fatigue of nitrided $18 \mathrm{Ni}$ maraging steel sheet. Int J Fatigue. 2014;64:140-146.

22. Murakami Y, Nomoto T, Ueda T. On the mechanism of fatigue failure in the superlong life regime ( $\mathrm{N}>107$ cycles). Part II: a fractographic investigation. Fatigue Fract Eng Mater Struct. 2000;23:903-910.

23. Shiozawa K, Morii Y, Nishino S, Lu L. Subsurface crack initiation and propagation mechanism in high-strength steel in a very high cycle fatigue regime. Int J Fatigue. 2006;28:1521-1532.

24. Sakai T, Nakagawa A, Oguma N, et al. A review on fatigue fracture modes of structural metallic materials in very high cycle regime. Int J Fatigue. 2016;93:339-351.

25. Zhao P, Gao G, Misra RDK, Bai B. Effect of microstructure on the very high cycle fatigue behavior of a bainite/martensite multiphase steel. Mater Sci Eng A. 2015;630:1-7.

26. Pineau A, Forest S. Effects of inclusions on the very high cycle fatigue behaviour of steels. Fatigue Fract Eng Mater Struct. 2017;40:1694-1707.
27. Mughrabi $\mathrm{H}$. On the life-controlling microstructural fatigue mechanisms in ductile metals and alloys in the gigacycle regime. Fatigue Fract Eng Mater Struct. 1999;22:633-641.

28. Mughrabi H. Cyclic slip irreversibilities and the evolution of fatigue damage. Metall Mater Trans B Process Metall Mater Process Sci. 2009;40:431-453.

29. Höppel HW, Prell MP, May L, Göken M. Influence of grain size and precipitates on the fatigue lives and deformation mechanisms in the VHCF regime. Procedia Engineering. 2010;2:10251034.

30. Stanzl-Tschegg SE. Fracture mechanical characterization of the initiation and growth of interior fatigue cracks. Fatigue Fract Eng Mater Struct. 2017;40:1741-1751.

31. Gao G, Zhang B, Cheng C, Zhao P, Zhang H, Bai B. Very high cycle fatigue behaviors of bainite/martensite multiphase steel treated by quenching-partitioning-tempering process. Int $J$ Fatigue. 2016;92:203-210.

32. Chai G. The formation of subsurface non-defect fatigue crack origins. Int J Fatigue. 2006;28:1533-1539.

33. Tofique MW, Bergström J, Burmann C. Very high cycle fatigue crack initiation mechanisms in different engineering alloys. Procedia Structural Integrity. 2016;2:1181-1190.

34. Krupp U., Giertler A. and Koschella K. The significance of microstructure inhomogeneities during VHCF of tempered martensitic steel., in proceeding of VHCF7 Conference, 2017, July 3-5, Dresden, Germany, 107-112.

35. Duan Z, Ma XF, Shi HJ, Murai R, Yanagisawa E. Gigacycle fatigue behaviors of two SNCM439 steels with different tensile strengths. Acta Mech Sin Xuebao. 2011;27:778-784.

36. Zettl B, Mayer H, Ede C, Stanzl-Tschegg S. Very high cycle fatigue of normalized carbon steels. Int $J$ Fatigue. 2006;28:1583-1589.

37. Mayer H, Schuller R, Karr U, et al. Cyclic torsion very high cycle fatigue of VDSiCr spring steel at different load ratios. Int J Fatigue. 2015;70:322-327.

38. Akiniwa Y, Stanzl-Tschegg S, Mayer H, Wakita M, Tanaka K. Fatigue strength of spring steel under axial and torsional loading in the very high cycle regime. Int J Fatigue. 2008;30:20572063.

39. Mayer H, Haydn W, Schuller R, Issler S, Bacher-Höchst M. Very high cycle fatigue properties of bainitic high carbon-chromium steel under variable amplitude conditions. Int J Fatigue. 2009;31:1300-1308.

40. Pyttel B, Schwerdt D, Berger C. Fatigue strength and failure mechanisms in the VHCF-region for quenched and tempered steel $42 \mathrm{CrMoS} 4$ and consequences to fatigue design. Procedia Eng. 2010;2:1327-1336.

41. Schneider N, Bödecker J, Berger C, Oechsner M. Frequency effect and influence of testing technique on the fatigue behaviour of quenched and tempered steel and aluminium alloy. Int J Fatigue. 2016;93:224-231.

42. Furuya Y, Matsuoka S. Improvement of gigacycle fatigue properties by modified ausforming in 1600 and 2000 MPA-class lowalloy steels. Metall Mater Trans A. 2002;33:3421-3431. 
43. Jiang Q, Sun C, Liu X, Hong Y. Very-high-cycle fatigue behavior of a structural steel with and without induced surface defects. Int J Fatigue. 2016;93:352-362.

44. Nishijima S, Kanazawa K. Stepwise S-N curve and fish-eye failure in gigacycle fatigue. Fatigue Fract Eng Mater Struct. 1999;22:601-607.

45. AFNOR. NF A03-400 Essais de fatigue. 1983.

46. Boyer HE. Atlas of fatigue curves, Edited by ASM International 1985:518.

47. Lu LT, Zhang JW, Shiozawa K. Influence of inclusion size on S$\mathrm{N}$ curve characteristics of high-strength steels in the giga-cycle fatigue regime. Fatigue Fract Eng Mater Struct. 2009;32:647-655.

48. Murakami Y, Takada M, Toriyama T. Fatigue. Super-long life tension-compression fatigue properties of quenched and tempered 0.46\% carbon steel. International J Fatigue. 1998;19:661667.

49. Marines I, Bin X, Bathias C. An understanding of very high cycle fatigue of metals. Int J Fatigue. 2003;25:1101-1107.

50. Itoga H, Tokaji K, Nakajima M, Ko HN. Effect of surface roughness on step-wise S-N characteristics in high strength steel. Int J Fatigue. 2003;25:379-385.

51. Suh C-M, Kim J-H. Fatigue characteristics of bearing steel in very high cycle fatigue. J Mech Sci Technol. 2010;23:420-425.

52. Schuller R, Karr U, Irrasch D, et al. Mean stress sensitivity of spring steel in the very high cycle fatigue regime. J Mater Sci. 2015;50:5514-5523.

53. Furuya Y, Matsuoka S. Gigacycle fatigue properties of a modified-ausformed Si-Mn steel and effects of microstructure. Metall Mater Trans A. 2004;35:1715-1723.

54. Furuya Y. Specimen size effects on gigacycle fatigue properties of high-strength steel under ultrasonic fatigue testing. Scr Mater. 2008;58:1014-1017.

55. Furuya Y, Abe T, Matsuoka S. 1010-cycle fatigue properties of $1800 \mathrm{MPa}$-class JIS-SUP7 spring steel. Fatigue Fract Eng Mater Struct. 2003;26:641-645.

56. Furuya Y, Hirukawa H, Hayakawa M. Gigacycle fatigue properties of hydrogen-charged JIS-SCM440 low-alloy steel under ultrasonic fatigue testing. Metall Mater Trans A Phys Metall Mater Sci. 2010;41:2248-2256.

57. Nie YH, Fu WT, Hui WJ, Dong H, Weng YQ. Very high cycle fatigue behaviour of 2000-MPa ultra-high-strength spring steel with bainite-martensite duplex microstructure. Fatigue Fract Eng Mater Struct. 2009;32:189-196.

58. Shimamura Y, Kokubo A, Ishii H, et al. Fatigue properties of carburized alloy steel in very high cycle regime under torsional loading. Int J Fatigue. 2014;60:57-62.

59. Bach J, Möller JJ, Göken M, Bitzek E, Höppel HW. On the transition from plastic deformation to crack initiation in the highand very high-cycle fatigue regimes in plain carbon steels. Int J Fatigue. 2016;93:281-291.

60. Zhong-Guang W, Rahka K, Nenonen P, Laird C. Changes in morphology and composition of carbides during cyclic deformation at room and elevated temperature and their effect on mechanical properties of CrMoV steel. Acta Metall. 1985;33:2129-2141.
61. Mareau C, Favier V, Weber B, Galtier A, Berveiller M. Micromechanical modeling of the interactions between the microstructure and the dissipative deformation mechanisms in steels under cyclic loading. International Journal of Plasticity. 2012;32-33:106-120.

62. Bathias C. Influence of the metallurgical instability on the gigacycle fatigue regime. International Journal of Fatigue. 2010;32:535-540.

63. Murakami Y, Usuki H. Quantitative-evaluation of effects of non-metallic inclusions on fatigue-strength of high-strength Steels.2. Fatigue limit evaluation based on statistics for extreme values of inclusion size. Int J Fatigue. 1989;11:299-307.

64. Murakami Y. Material defects as the basis of fatigue design. Int J Fatigue. 2012;41:2-10.

65. Roiko A, Murakami Y. A design approach for components in ultralong fatigue life with step loading. Int $J$ Fatigue. 2012;41:140-149.

66. Sakai T. Review and prospects for current studies on very high cycle fatigue of metallic materials for machine structural use. $J$ Solid Mech Mater Eng. 2009;3:425-439.

67. Grad P, Reuscher B, Brodyanski A, Kopnarski M, Kerscher E. Mechanism of fatigue crack initiation and propagation in the very high cycle fatigue regime of high-strength steels. Scr Mater. 2012;67:838-841.

68. Shanyavskiy AA. Mechanisms and modeling of subsurface fatigue cracking in metals. Engineering Fracture Mechanics. 2013;110:350-363.

69. Hong Y, Liu X, Lei Z, Sun C. The formation mechanism of characteristic region at crack initiation for very-high-cycle fatigue of high-strength steels. Int J Fatigue. 2016;89:108-118.

70. Nakajima M, Kamiya N, Itoga H, Tokaji K, Ko HN. Experimental estimation of crack initiation lives and fatigue limit in subsurface fracture of a high carbon chromium steel. Int $J$ Fatigue. 2006;28:1540-1546.

71. Yang ZG, Zhang JM, Li SX, et al. On the critical inclusion size of high strength steels under ultra-high cycle fatigue. Mater Sci Eng A. 2006;427:167-174.

72. Furuya Y, Hirukawa H, Kimura T, Hayaishi M. Gigacycle fatigue properties of high-strength steels according to inclusion and ODA sizes. Metall Mater Trans A Phys Metall Mater Sci. 2007;38:1722-1730.

73. Murakami Y. Metal Fatigue: Effects of Small Defects and Non Metallic Inclusions. 3 London: Elsevier; 2002.

74. Murakami Y, Ueda T, Nomoto T. Fractographic analysis of fatigue failure in the superlong life regime of $\mathrm{N}>10 \exp 7$ cycles. ECF 13--13 Th. Eur. Conf. 2000:893-902.

75. Karsch T, Bomas H, Zoch HW, Mändl S. Influence of hydrogen content and microstructure on the fatigue behaviour of steel SAE 52100 in the VHCF regime. Int J Fatigue. 2014;60:74-89.

76. Endo K, Miyao Y. Effects of cyclic frequency on the corrosion fatigue strength. Bull Japan Soc Mech Eng. 1958;1:34

77. Ebara R, Yamada Y. Corrosion Fatigue Behavior of $13 \mathrm{Cr}$ stainless steel and Ti-6Al-4V at ultrasonic frequency. In: Wells (Westinghouse), Buck JM, Roth, Tien, eds. Ultrasonic fatigue. New York: The Metallurgical Society of AIME; 1982:349-364. 
78. Palin-Luc T, Perez-Mora R, Bathias C, Dominguez G, Paris PC, Arana J-L. Fatigue crack initiation and growth on a steel in the very high cycle regime with sea water corrosion. Engineering Fracture Mechanics. 2010;77:1953-1962.

79. Schönbauer BM, Stanzl-Tschegg SE, Perlega A, et al. Fatigue life estimation of pitted $12 \% \mathrm{Cr}$ steam turbine blade steel in different environments and at different stress ratios. Int J Fatigue. 2014;65:33-43.

80. Perez-Mora R, Palin-Luc T, Bathias C, Paris PC. Very high cycle fatigue of a high strength steel under sea water corrosion: a strong corrosion and mechanical damage coupling. International Journal of Fatigue, Volume. 2015;74(May 2015):156-165.

81. Ebara R. Some influencing variables on internal fatigue crack initiation in structural materials. Fatigue Fract Eng Mater Struct. 2017;40:1752-1761.

82. Stanzl-Tschegg S. Very high cycle fatigue measuring techniques. Int J Fatigue. 2014;60:2-17.

83. Lang KH, Korn M, Rohm T. Very high cycle fatigue resistance of the low alloyed steel $42 \mathrm{CrMo} 4$ in medium and high-strength quenched and tempered condition. Procedia Structural Integrity. 2016;2:1133-1142.

84. Brand A, Flavenot J-F, Grégoire R, Tournier C. Recueil de données technologiques sur la fatigue. CETIM France; 1980.

85. Coupard D, Palin-luc T, Bristiel P, Ji V, Dumas C. Residual stresses in surface induction hardening of steels: comparison between experiment and simulation. Mater Sci Eng A. 2008;487:328-339.

86. Palin-Luc T, Coupard D, Dumas C, Bristiel P. Simulation of multiaxial fatigue strength of steel component treated by surface induction hardening and comparison with experimental results. Int J Fatigue. 2011;33:1040-1047.

87. Jeddi D, Lieurade H-P. Effect of retained austenite on high cycle fatigue behavior of carburized $14 \mathrm{NiCr} 11$ steel. Procedia Eng. 2010;2:1927-1936.

88. Tanaka K, Akiniwa Y. Fatigue crack propagation behaviour derived from S-N data in very high cycle regime. Fatigue Fract Eng Mater Struct. 2002;25:775-784.

89. Jeddi D, Sidhom H, Ghiglione D, Lieurade H-P. Role of the cyclic stability of retained austenite in fatigue performance of carburized 14NiCr11 steel. J Mater Eng Perform. 2005;14:

90. Lu J, Flavenot JF. Relaxation des contraintes résiduelles sous chargement cyclique. Influence des caractéristiques mécaniques et prévision par le calcul. Rev Métallurgie. 1988;615-626.

91. Crossland B. Effect of Large Hydrostatic Pressures on the Torsional Fatigue Strength of an Alloy Steel. London: Int Conf Fatigue Met; 1956.

92. Skally N, Flavenot JF. Prise en compte des contraintes résiduelles dans un calcul prévisionnel de tenue en fatigue. CETIM Information. 1985;90:35-47.

93. Kovacs S, Beck T, Singheiser L. Influence of mean stresses on life and damage of a turbine blade steel in the VHCF-regime. Int J Fatigue. 2013;49:90-99.
94. Sun C, Zhang X, Liu X, Hong Y. Effects of specimen size on fatigue life of metallic materials in high-cycle and very-highcycle fatigue regimes. Fatigue Fract Eng Mater Struct. 2016;39:770-779.

95. Furuya Y, Matsuoka S, Abe T, Yamaguchi K. Gigacycle fatigue properties for high-strength low-alloy steel at $100 \mathrm{~Hz}, 600 \mathrm{~Hz}$, and $20 \mathrm{kHz}$. Scr Mater. 2002;46:157-162.

96. Paolino DS, Tridello A, Chiandussi G, Rossetto M. On specimen design for size effect evaluation in ultrasonic gigacycle fatigue testing. Fatigue Fract Eng Mater Struct. 2014;37:570-579.

97. Nakajima M, Tokaji K, Itoga H, Shimizu T. Effect of loading condition on very high cycle fatigue behavior in a high strength steel. Int J Fatigue. 2010;32:475-480.

98. Takeuchi E, Furuya Y, Nagashima N, Matsuoka S. The effect of frequency on the giga-cycle fatigue properties of a Ti-6Al-4V alloy. Fatigue Fract Eng Mater Struct. 2008;31:599-605.

99. Urabe N, Weertman J. Dislocation mobility in potassium and iron single crystals. Mater Sci Eng. 1975;18:41-49.

100. Lee W-S, Liu C-Y. The effects of temperature and strain rate on the dynamic flow behaviour of different steels. Mater Sci Eng A. 2006;426:101-113.

101. Torabian N, Favier V, Dirrenberger J, Adamski F, Ziaei-Rad S, Ranc N. Correlation of the high and very high cycle fatigue response of ferrite based steels with strain rate temperature conditions. Acta Mater. 2017;134:40-52.

102. Ritz F, Beck T. Influence of mean stress and notches on the very high cycle fatigue behaviour and crack initiation of a low-pressure steam turbine steel. Fatigue Fract Eng Mater Struct. 2017;40:1762-1771.

103. Papadopoulos IV, Panoskaltsis VP. Invariant formulation of a gradient dependent multiaxial high-cycle fatigue criterion. Eng Fract Mech. 1996;55:513-528.

104. Ogawa T, Stanzl-Tschegg SE, Schönbauer BM. A fracture mechanics approach to interior fatigue crack growth in the very high cycle regime. Eng Fract Mech. 2014;115:241-254.

105. Bathias C. Piezoelectric fatigue testing machines and devices. Int J Fatigue. 2006;28:1438-1445.

106. Sakai T, Sakai T, Okada K, Furuichi M, Nishikawa I, Sugeta A. Statistical fatigue properties of SCM435 steel in ultra-long-life regime based on JSMS database on fatigue strength of metallic materials. Int J Fatigue. 2006;28:1486-1492.

107. Fitzka M, Catoor D, Irrasch D, Reiterer M, Mayer H. Ultrasonic fatigue testing of thin MP35N alloy wire. Procedia Struct Integr. 2016;2:1039-1046.

108. Mintz B, Wilson DV. Strain ageing during the fatigue of carbon steels. Acta Metall. 1965;13:947-956.

How to cite this article: Jeddi D, Palin-Luc T. A review about the effects of structural and operational factors on the gigacycle fatigue of steels. Fatigue Fract Eng Mater Struct. 2018;41:969-990. https://doi.org/10.1111/ffe.12779 